\title{
Nanocapsule-delivered Sleeping Beauty mediates therapeutic Factor VIII expression in liver sinusoidal endothelial cells of hemophilia A mice
}

\author{
Betsy T. Kren,1 Gretchen M. Unger, ${ }^{2}$ Lucas Sjeklocha, ${ }^{1}$ Alycia A. Trossen, ${ }^{1}$ Vicci Korman, ${ }^{2}$ \\ Brenda M. Diethelm-Okita, ${ }^{1}$ Mark T. Reding, ${ }^{1}$ and Clifford J. Steer ${ }^{1,3}$ \\ ${ }^{1}$ Department of Medicine, University of Minnesota Medical School, Minneapolis, Minnesota, USA. ${ }^{2}$ GeneSegues Inc., Chaska, Minnesota, USA. \\ ${ }^{3}$ Department of Genetics, Cell Biology, and Development, University of Minnesota Medical School, Minneapolis, Minnesota, USA.
}

\begin{abstract}
Liver sinusoidal endothelial cells are a major endogenous source of Factor VIII (FVIII), lack of which causes the human congenital bleeding disorder hemophilia A. Despite extensive efforts, gene therapy using viral vectors has shown little success in clinical hemophilia trials. Here we achieved cell type-specific gene targeting using hyaluronan- and asialoorosomucoid-coated nanocapsules, generated using dispersion atomization, to direct genes to liver sinusoidal endothelial cells and hepatocytes, respectively. To highlight the therapeutic potential of this approach, we encapsulated Sleeping Beauty transposon expressing the B domain-deleted canine FVIII in cis with Sleeping Beauty transposase in hyaluronan nanocapsules and injected them intravenously into hemophilia A mice. The treated mice exhibited activated partial thromboplastin times that were comparable to those of wild-type mice at 5 and 50 weeks and substantially shorter than those of untreated controls at the same time points. Further, plasma FVIII activity in the treated hemophilia A mice was nearly identical to that in wild-type mice through 50 weeks, while untreated hemophilia A mice exhibited no detectable FVIII activity. Thus, Sleeping Beauty transposon targeted to liver sinusoidal endothelial cells provided long-term expression of FVIII, without apparent antibody formation, and improved the phenotype of hemophilia A mice.
\end{abstract}

\section{Introduction}

The delivery of genes to treat metabolic disease resulting from a defective or absent protein remains a significant challenge in medicine. Hemophilia A is an X-linked congenital bleeding disorder caused by deficiency of coagulation Factor VIII (FVIII), affecting approximately 1 in every 5,000-10,000 males worldwide. It has been a major focus of gene replacement strategies, using primarily virus-based vectors for in vivo gene delivery (1). However, due to the lack of success with viral vectors in clinical hemophilia trials $(2,3)$ and adverse events in other viral vector patient trials $(4,5)$, efforts have been revitalized to develop nonviral vectors and delivery systems for therapeutic use (6).

While the hydrodynamic method for nonviral gene therapy to liver has been used effectively in recent years (7), the practical nature of its clinical application remains a concern. Moreover, this hepatic deliv-

Conflict of interest: The authors have declared that no conflict of interest exists.

Nonstandard abbreviations used: AFM, atomic force microscopy; aPTT, activated partial thromboplastin time; ASGPr, asialoglycoprotein receptor; ASOR, asialoorosomucoid; B $\Delta \mathrm{cFVIII}$, canine B domain-deleted FVIII; CAGGS, hybrid CMV enhancer: chicken $\beta$-actin; CDS, coding sequence; $\mathrm{CPG}$, cytosine-guanine dinucleotide; dNTP, deoxyribonucleotide triphosphate; DsRed2, Discoma sp. red fluorescent protein version 2; FVIII, Factor VIII; FIXa, activated Factor IX; FX, Factor X; FXa, activated FX; HA, hyaluronan; HARE, HA receptor for endocytosis; IF, mouse eukaryotic initation factor 4A1 promoter; IHC, immunohistochemistry; IR/DR, inverted repeat/direct repeat; lacZ, prokaryotic $\beta$-galactosidase gene; LSEC, liver sinusoidal endothelial cell; PEI, polyethylenimine; pSV40:Alb-lacZ, SV40:Alb lacZ plasmid; pSV40:Ear-lacZ, SV40: Ear lacZ plasmid; pT2, second version of Tn; s50, (nanocapsules) less than $50 \mathrm{~nm}$ in diameter; $S B$, Sleeping Beauty; $S B 10, S B$ transposase version 10; $S B-\mathrm{Tn}, S B$ transposon; SV40:Alb, hepatocyte-specific SV40 enhancer:albumin hybrid; SV40:Ear, constitutive SV0 enhancer:early; TEM, transmission electron microscopy; Tn, transposon. Citation for this article: J. Clin. Invest. 119:2086-2099 (2009). doi:10.1172/JCI34332 ery method is not cell type specific, delivering DNA to hepatocytes, Kupffer cells, and liver sinusoidal endothelial cells (LSECs) (8). There is strong evidence to suggest that LSECs are the endogenous site of FVIII production within the liver $(9,10)$; and formation of neutralizing inhibitory Abs (inhibitors) to FVIII may, in part, be dependent on the cell type for transgene expression (11-13).

Although significant advances have been made in developing nonviral episomal plasmid vectors that achieve long-term expression (14), genomic insertion of transgenes has the potential for permanent expression. The resurrection of an ancient vertebrate transposon ( $\mathrm{Tn}$ ) system, Sleeping Beauty $(S B)$ has provided a nonviral vector system allowing efficient insertion of transgenes into the host genome. It has been used successfully for both gene replacement (15) and gene discovery in mice (16); and integrates transgenes at a frequency comparable with that of viral vectors in both quiescent and replicating cells $(17,18)$. The Tn inserts into a genomic TA dinucleotide using a cut-and-paste mechanism catalyzed by the obligate $S B$ transposase, which can be supplied either as a 2-plasmid (trans) system or as a single plasmid in cis carrying the expression cassette for the transposase external to the inverted repeat/direct repeat-flanked (IR/DR-flanked) transgene $(19,20)$.

In this study, we developed selective hepatic cell delivery systems using receptors that are unique to and highly expressed by hepatocytes or LSECs. We targeted the hepatocyte asialoglycoprotein receptor (ASGPr) using its natural ligand, asialoorosomucoid (ASOR) (21), while LSECs were targeted using hyaluronan (HA), the endogenous ligand for the HA receptor for endocytosis (HARE) (22). We developed an atomization method to prepare nanocapsules of less than 50 in diameter for delivery of plasmids 


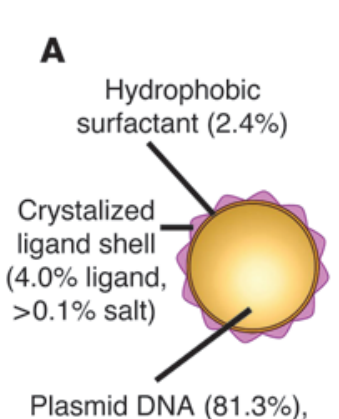

PEI (12.2\%)
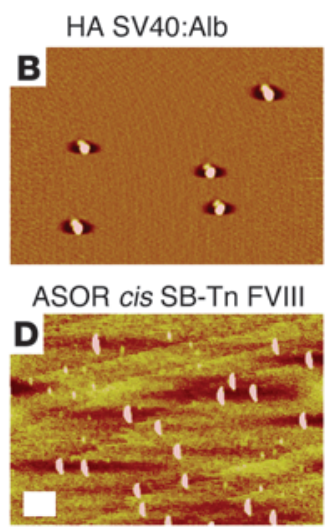

ASOR SV40:Ear

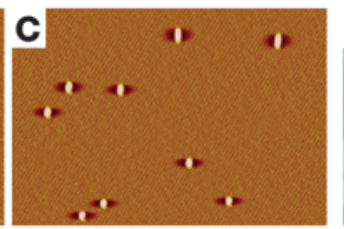

HA cis SB-Tn FVIII

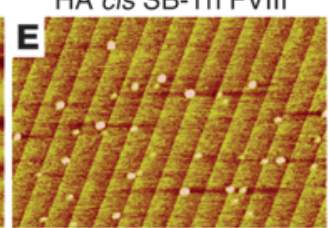

ASOR SV40:Ear

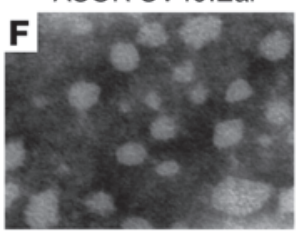

HA SV40:Alb

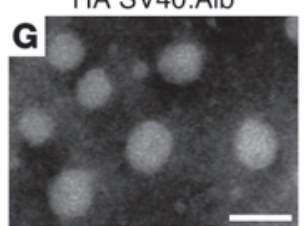

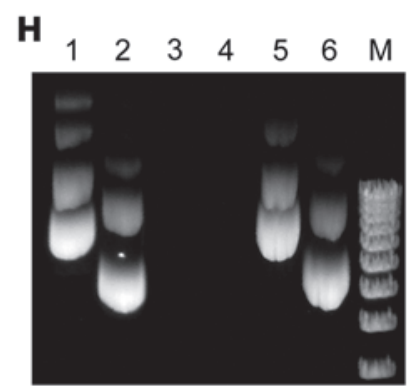

\section{Figure 1}

Size analysis and DNase protection of plasmids encapsulated by dispersion atomization. (A) Schematic of the s50 capsule showing the overall structure and composition. The percentage of each constituent in the final formulated nanocapsule is indicated in parentheses. PEI, 25-kDa polyethylenimine. (B-E) Atomic force micrographs of HA-encapsulated pSV40:Alb-lacZ (B); ASOR-encapsulated pSV40:Ear-lacZ (C); ASORencapsulated cis SB-Tn/CAGGS-B $\Delta$ cFVIII (D); and HA-encapsulated cis SB-Tn/CAGGS-B $\Delta$ cFVIII (E) prepared as described in Methods. The size of the ASOR ( $C$ and $\mathbf{D}$ ) and HA (B and $\mathbf{E})$ nanocapsules with plasmids was determined by AFM image analysis using data collected in the tapping mode. Scale bar: $100 \mathrm{~nm}$. Transmission electron micrographs of negatively stained ASOR-encapsulated pSV40:Ear-lacZ (F) and HAencapsulated pSV40:Alb-lacZ (G). Scale bar: $50 \mathrm{~nm}$. (H) DNase resistance of plasmid DNA in ASOR or HA nanocapsules. Plasmid DNA (1 $\mu \mathrm{g}$ ) with or without encapsulation was subjected to DNase treatment and the DNA recovered as outlined in Methods. A 0.5- $\mu$ g aliquot of DNA was separated on a $0.7 \%$ agarose gel and the plasmids visualized by ethidium bromide staining and UV light. Lane 1, pSV40:Ear-lacZ untreated; lane 2, pSV40:Alb-lacZ untreated; lane 3, pSV40:Ear-lacZ; lane 4, pSV40:Alb-lacZ; lane 5, pSV40:Ear-lacZ in ASOR nanocapsules; and lane 6, pSV40:Alb-lacZ in HA nanocapsules; lanes 3-6, treated. M, 1-kb ladder (Invitrogen).

ranging in size from 5.2 to $12.8 \mathrm{~kb}$ and coated with targeting ligand, e.g. ASOR or HA, and stabilized by a crystallization step to create a protective, shielding shell with a neutral charge and a nonordered surface. Cell-specific LSEC and hepatocyte targeting in vivo by HA and ASOR nanocapsules, respectively, was confirmed in mice by the use of reporter genes. We then targeted LSECs in adult knockout hemophilia A mice using HA-encapsulated cis $S B$ transposon ( $S B-\mathrm{Tn}$ ) vectors containing the canine $B$ domain-deleted FVIII (B $\Delta$ cFVIII) gene (23) driven by the constitutive hybrid CMV enhancer:chicken $\beta$-actin (CAGGS) promoter (24). Correction of the bleeding diathesis in the treated mice occurred as early as 1 week after treatment and was sustained for 50 weeks, with no detection of FVIII inhibitors. Our data suggest that in vivo delivery of cis SB-Tns to LSECs provides a clinically applicable method for promoting $S B$-mediated stable gene transfer and efficient expression of FVIII for potential use in gene therapy strategies for hemophilia A.

\section{Results}

Encapsulation of plasmids by dispersion atomization. The size of the particle used to deliver plasmid DNA in vivo may be critical for ensuring that uptake is receptor mediated and cell type specific (25). Thus, we characterized the size of the HA- and ASOR-encapsulated plasmids by atomic force microscopy (AFM) and transmission electron microscopy (TEM). Representative micrographs (Figure 1, B-E) from AFM showed that the particles were less than 50 $\mathrm{nm}$ in diameter (s50), even with the encapsulated $12.8-\mathrm{kb}$ cis $S B-\mathrm{Tn}$ CAGGS-B $\Delta$ cFVIII transgene (Tables 1 and 2). Moreover, the formulation process was robust, with only small variations observed in the size of the encapsulated cis $S B$-Tn CAGGS-B $\Delta$ cFVIII with the same coating protein. The size was also assessed by TEM following negative staining of the encapsulated plasmids (Figure 1, F and G), confirming that the diameter was less than $50 \mathrm{~nm}$.
In addition to size, the overall net charge of the nanocapsules is important in reducing nonspecific attraction of serum proteins (26) and toxicity (27) and mediating receptor-specific uptake (28) in vivo. Therefore the overall net charge of the HA and ASOR plasmid nanoparticles was investigated using a Malvern Zetasizer 4 and found to be negative or neutral for the HA and ASOR targeted particles, irrespective of plasmid size (Table 1). The different formulation batches of the ASOR and HA cis $S B$-Tn CAGGS-B $\Delta$ cFVIII demonstrate that an overall negative-to-neutral charge was consistently achieved (Table 2).

Finally, it is essential that any delivery system protect its DNA cargo from nucleases prior to cell and nuclear uptake. We investigated the ability of HA and ASOR nanocapsules to protect plasmids from DNase digestion in vitro. The results indicated that the ASOR-encapsulated plasmid SV40 early- $\beta$-galactosidase (pSV40:Ear-lacZ) (Figure 1H, lane 5) and the plasmid SV40:albumin- $\beta$-galactosidase (pSV40:Alb-lacZ) HA (Figure 1H, lane 6) were protected for more than 12 hours from DNase I digestion at $37^{\circ} \mathrm{C}$. In contrast, equal amounts of nonencapsulated plasmids were completely degraded (Figure 1H, lanes 3 and 4).

In addition to nuclease protection, the efficiency of plasmid encapsulation is important in developing an efficient in vivo delivery system. Thus, mean encapsulation was determined using the Burton method for quantitation of encapsulated DNA. ASOR and HA gave similar encapsulation efficiencies of $87.0 \% \pm 4.2 \%$ for the plasmids expressing Discoma sp. red fluorescent protein version 2 (DsRed2). The independent formulation runs of the cis SB-Tn CAGGS-B $\Delta$ cFVIII plasmids indicated more than $90 \%$ encapsulation efficiency in all but a single batch using HA (Table 2). Taken together, these data indicate that the formulation method was able to reproducibly encapsulate $89 \% \pm 16 \%$ of the starting plasmid, irrespective of whether the coating protein was HA, ASOR, or an alternate. 


\section{Table 1}

Plasmid constructs and nanocapsule characteristics

\begin{tabular}{|c|c|c|c|c|c|c|c|c|}
\hline \multirow[t]{3}{*}{ Plasmid } & \multirow[t]{3}{*}{ Promoter } & \multirow[t]{3}{*}{ Gene } & \multirow{3}{*}{$\begin{array}{l}\text { Size } \\
\text { (kb) }\end{array}$} & \multirow[t]{3}{*}{ Reference } & \multicolumn{4}{|c|}{ Nanocapsule ligand } \\
\hline & & & & & \multicolumn{2}{|c|}{ ASOR } & \multicolumn{2}{|c|}{ HA } \\
\hline & & & & & Size (nm) & Charge (meV) & Size $(\mathrm{nm})$ & Charge (meV) \\
\hline $\begin{array}{l}\text { pT2/CAGGS-DsRed2/ } \\
\text { /CMVSB10 }\end{array}$ & CAGGS & DsRed2 & 8.6 & 19,24 & $21 \pm 2^{A}$ & $-8.6 \pm 2.8^{B}$ & $20 \pm 2$ & $-4.6 \pm 4.5$ \\
\hline pDrive-SV40-bAlb & $\begin{array}{l}\text { SV40 enhancer: } \\
\text { bovine albumin promoter }\end{array}$ & lacZ & 6.8 & 80 & $27 \pm 2$ & $-0.8 \pm 1.7$ & $22 \pm 2$ & $-1.8 \pm 3.7$ \\
\hline pSV- $\beta$-gal & SV40 enhancer and promoter & lacZ & 5.2 & 81 & $29 \pm 2$ & $-1.8 \pm 3.5$ & NA & NA \\
\hline
\end{tabular}

AMean \pm SEM of the average elliptical axis determined from AFM micrographs of 25 capsules from 2 different preparations in a single manufacturing run. BAverage surface charge in millielectron volts ( $\mathrm{meV}$ ) measured by dynamic light scattering (DLS) from 2 different preparations in a single manufacturing run. Data are the mean \pm SEM of 15 independent measurements. NA, not available.

Cell-selective hepatic delivery of SB-Tns using ASOR or HA nanocapsules. It was critical to establish that ligand-targeted nanocapsules were able to provide cell-specific delivery to liver. Thus, we used a cis $S B$-Tn expressing the DsRed2 reporter under control of the CAGGS promoter using the rabbit $\beta$-globin 3 ' untranslated region (UTR) and poly(A) signal $(19,24)$. The plasmids were encapsulated using either HA or ASOR as targeting ligand and administered to mice via tail vein injection. The animals were sacrificed at 1 week and the liver and other organs excised and processed for immunohistochemistry (IHC) and Western blot analysis. Confocal fluorescent microscopy of liver from HA- or ASOR-treated or control animals was performed after IHC using anti-CD14 as a marker for LSECs (29). The results indicated that when ASOR was used as targeting ligand (Figure 2A, top row), DsRed2 was expressed in hepatocytes and exhibited no apparent colocalization with CD14. In contrast, with HA cis DsRed2 SB-Tns, there was no detectable red fluorescence expression in hepatocytes (Figure 2A, middle row) but substantial colocalization of DsRed 2 and CD14 signals in LSECs. No red fluorescence was observed in control livers, while the endogenous CD14 distribution mirrored that of the treated animals (Figure 2A, bottom row). No other organs (lung, kidney, spleen, heart, and gonads) from either the DsRed2 $S B$-Tn ASOR- or HA-treated mice gave DsRed2 fluorescence (data not shown). We investigated additional galactose-presenting ligands to the hepatocyte ASGPr, including $N$-acetylgalactosamine, asialo-galactotriantennary, and arabinogalactan. In contrast to the hepatocyte-specific targeting observed with the ASOR ligand, there was considerable nonspecific uptake of nanocapsules in other organ tissues, perhaps via alternate receptors (30) (data not shown).

Western blot analysis of total protein extracts was performed and confirmed the results from confocal microscopy. DsRed2 protein was readily detectable in livers of mice that had been treated with either the HA- or ASOR-encapsulated cis DsRed2 Tn plasmid, while none was detected in control livers (Figure 2B). In contrast, no DsRed2 protein was found in kidney,

Table 2

spleen, or lung from either the DsRed2 SB-Tn-treated or control mice (Figure 2C).

To validate cell-specific liver targeting, we used a hepatocyte-specific SV40 enhancer:albumin hybrid (SV40:Alb) promoter- or the constitutive SV40 enhancer:early (SV40:Ear) promoter-driven prokaryotic $\beta$-galactosidase gene (lacZ). The pSV40:Alb-lacZ encapsulated with HA or ASOR and the pSV40:Ear-lacZ targeted to hepatocytes with ASOR were administered to mice weighing approximately $20 \mathrm{~g}$ via tail vein injection. The animals were sacrificed after 1 week and the liver and other organs removed and processed for histology as well as DNA and RNA isolation. Prokaryotic lacZ expression in liver cryosections was determined by IHC using anti- $\beta$-gal $A b$. The results indicated that the hepatocyte-specific SV40:Alb promoter restricted expression of lacZ to hepatocytes irrespective of the targeting ligand (Figure 3, A-D). However, expression from both promoters was low relative to the strong CMV promoter routinely used for lac $\mathrm{Z}$ reporter studies, and some cross-reactivity of anti- $\beta$-gal Ab with control tissue was observed. Thus, we repeated the studies using pcDNA3.1, which expresses lacZ using the CMV enhancer/ promoter. It is fused in-frame with the Xpress protein tag, per-

Formulation reproducibility of cis SB-Tn/CAGGS-B $\Delta$ cFVIII nanocapsules

\section{Capsule-(cargo)}

ASOR-(cis SB-Tn/CAGGS-B $\Delta$ cFVIII)

No. $1,1229-18 \mathrm{i}$

No. $2,107-18 \mathrm{i}$

No. $3,322-18 \mathrm{i}$

No. 4 alternate, 6308-18i

$\mathrm{HA}-($ cis $S B-\mathrm{Tn} / \mathrm{CAGGS}-\mathrm{B} \Delta \mathrm{CFVIII})$

No. $1,704-11 \mathrm{n}$

No. $2,1229-11 n$

No. 3, 107-11n

No. $4,608-11 n$

\section{Surface charge $(\mathrm{meV})^{\mathrm{A}}$}

Particle diameter $(\mathrm{nm})^{\mathrm{B}}$
$18.6 \pm 7$

$17.1 \pm 7$

$19.6 \pm 6$

$-4.9 \pm 6$

$-4.6 \pm 5$

$-5.2 \pm 5$

$-8.4 \pm 6$

$-7.2 \pm 5$

$-8 \pm 5.6$
$19.7 \pm 7$

$24 \pm 8$

$13.6 \pm 4$

NA
Total DNA (\% encapsulation) ${ }^{\mathrm{C}}$

A $\zeta$ potential measured by DLS across a $20-\mathrm{V}$ potential in $1 \mathrm{mM} \mathrm{KCl}$ at $2 \mu \mathrm{g} / \mathrm{ml}$. Data are the mean \pm SEM from at least 15 independent measurements of 3 independent manufacturing runs. BParticle diameter measured by AFM as average elliptical diameter after drying at $0.5 \mathrm{ng} / \mathrm{ml}$. Data shown are the mean \pm SEM from at least 25 independent measurements of each of the 3 independent manufacturing runs. ${ }^{C}$ Total DNA measured using the Burton assay relative to the cis $S B-T n / C A G G S-B \Delta c F V I I I$ plasmid. Data are the mean \pm SEM from 3 duplicates from each lot. Encapsulation efficiency was determined as the percent plasmid encapsulated in the formulation of the $s 50$ coated particles. 
A
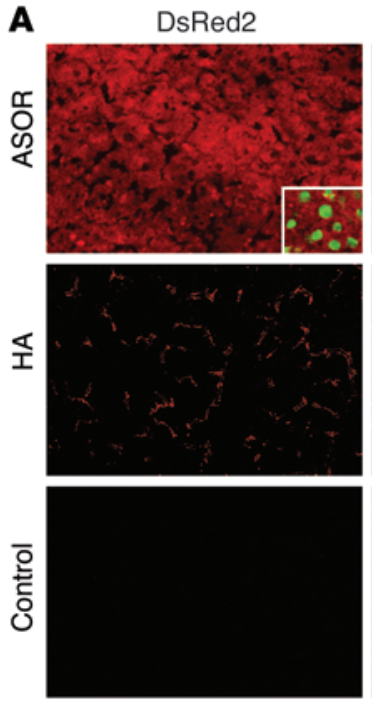

B

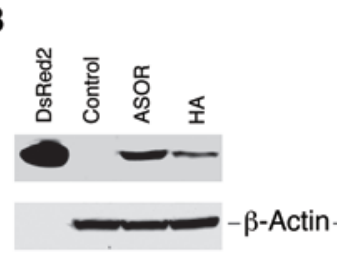

CD14 (LSEC)
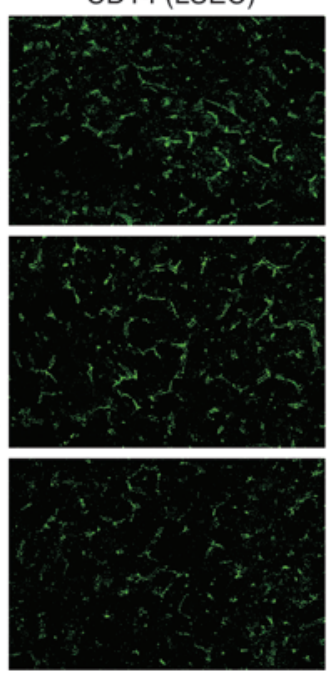

C

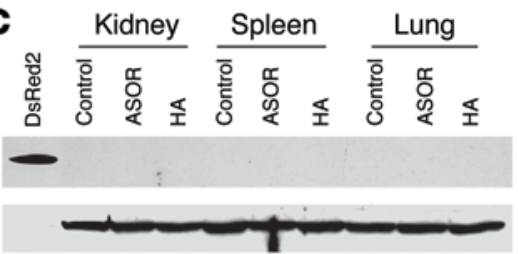

Merged
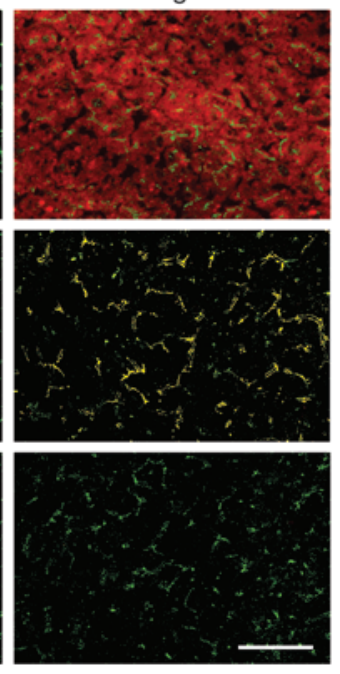

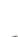

\section{Figure 2}

Delivery of nanoencapsulated DsRed2 SB-Tns in vivo to either hepatocytes or LSECs. Eight-week-old mice were administered $100 \mu \mathrm{g}$ of the encapsulated cis pT2/ DsRed2 Tns via tail vein injection and sacrificed 1 week after injection. Expression of DsRed2 targeted to hepatocytes with ASOR or to LSECs with HA was visualized by confocal microscopy. LSECs were identified by anti-CD14 Ab, a marker specific for the discontinuous endothelial cells in the liver, and a Cy5-labeled secondary Ab. The confocal micrographs (A) show Cy5-labeled LSECs (green) with DsRed2 fluorescence (red). The targeting ligand for the nanocapsules and the relevant protein are indicated at left and above, respectively. The merged images (right) of the DsRed2 and CD14 micrographs demonstrate colocalization (yellow) of fluorescence when HA was used as the targeting ligand. The inset in the top left panel shows SYTOX green-stained nuclei (green) of hepatocytes expressing DsRed2; original magnification, $\times 60$. Scale bar, $50 \mu \mathrm{m}$. (B) Western blot analysis of $100 \mu \mathrm{g}$ total liver protein extracts from control mice and mice treated with the ASOR or HA nanocapsules shown in $\mathbf{A}$. The proteins were detected by ECL as described in Methods. The treatment group is indicated above the lanes. (C) Western blot analysis of $100 \mu \mathrm{g}$ total protein extracts from kidney, spleen, and lung to determine nonspecific uptake of nanocapsules. The $\beta$-actin lanes for loading controls are shown below. Control, mice treated with HA nanocapsules not containing DsRed2-expressing SB-Tns; DsRed2, purified recombinant DsRed2 protein.

mitting visualization of the protein with Abs directed against the tag. Using this CMV-driven reporter, we observed high-level uniform expression at 1 week after injection in hepatocytes when the pcDNA3.1 was encapsulated with ASOR, while HA encapsulation led to uptake and expression in LSECs (Figure 3, E-J). DNA isolated from the livers of treated and control animals was subjected to PCR analysis to confirm delivery of the HA-encapsulated pSV40:AlblacZ. The livers of mice treated with HA-encapsulated SV40:AlblacZ plasmid showed similar levels of the predicted 345-bp amplicon (Figure 4A). However, no $\beta$-gal was expressed when pSV40: Alb-lacZ was targeted to the LSECs (Figure 4B, lane 1). In contrast, hepatocyte targeting with ASOR resulted in RT-PCR amplicons of the predicted size, irrespective of whether lac $Z$ was expressed from

the hepatocyte-specific or constitutive promoter (Figure $4 \mathrm{~B}$, lanes 2 and 3). No difference in expression or distribution of $\beta$-gal was observed between male and female mice (data not shown).

To establish the sensitivity of our lac $Z$ detection via PCR, we performed serial dilutions of the plasmid and subjected them to amplification using the same primers and conditions for the liver DNA. The results indicated that $0.05 \mathrm{pg}$ was reliably detected (Figure 4C, lane 5), while $0.01 \mathrm{pg}$ of plasmid template did not produce detectable amplicons (Figure 4C, lane 6). Quantitation of 4 independent dilution and amplification gels by densitometry gave a correlation coefficient for best fit of 0.998 (Figure 4D). Using this standard curve, we determined that amplicons derived from 3 independent liver DNA isolations in animals that received lacZ plasmids in either ASOR or HA nanocapsules delivered a mean of $0.1 \pm 0.01 \mathrm{pg}$ and $0.06 \pm 0.01$ pg per $0.5 \mu \mathrm{g}$ of liver DNA to the hepatocytes and LSECs, respectively.

The DNA isolated from other organs was subjected to PCR using the same primers and reaction conditions as per Figure 4A. No PCR products of the predicted 345 -bp size were amplified using $1.0 \mu \mathrm{g}$ of DNA isolated from lung, kidney, spleen, or testis of treated mice (Figure 4E), even though the apoB control was readily detectable with the same DNA template. Using more sensitive RT-PCR, we examined both the weaker constitutively expressed pSV40:Ear-lacZ as well as the stronger CMV-lacZ carried by pcDNA3.1/His/lacZ and targeted to the hepatocytes with ASOR encapsulation. Representative results (Figure 4F, left panel) from liver RT-PCR using $0.25 \mu \mathrm{g}$ of RNA from mice treated with pcDNA 3.1/His/lacZ showed the readily detectable amplification product of the lac $\mathrm{Z}$ mRNA. In contrast, none of the other organ RNA isolates demonstrated detectable products of the predicted 345-bp lacZ using $1.0 \mu \mathrm{g}$ of RNA as template.

We also investigated both short- and longer-term safety profiles of the HA and ASOR s50 nanocapsules. Acute toxicity was assessed in adult mice weighing approximately $20 \mathrm{~g} 72$ hours after tail vein administration of $200 \mu \mathrm{g}$ HA or ASOR encapsulated cis DsRed2 SB-Tn vectors. Standard blood chemistries (albumin, aspartate aminotransferase, alanine aminotransferase, urea nitrogen, total protein) and hemograms (wbc, rbc, hemoglobin, hematocrit, mean corpuscular volume, mean corpuscular hemoglobin, mean cell hemoglobin concentration, random distribution of rbc weight, platelet count) indicated no differences between treated and untreated groups (data not shown). Additional mice were sacrificed 3 months after receiving ASOR or HA nanocapsules containing pDrive-meIF4A1, and the liver and other organs (spleen, lung, kidney, heart) were excised and processed for paraffin embedding. The embedded organs were sectioned, stained with $\mathrm{H} \& \mathrm{E}$, and examined. No differences were observed between the treated mice and age-matched controls for any of the organs (data not shown). Taken together, the data suggested that the ASOR- and HA-encapsulated plasmids were not associated with any apparent adverse effects. 
HA SV40:Alb
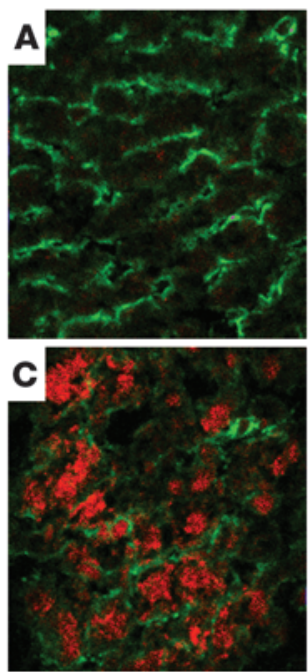

ASOR SV40:Ear
ASOR SV40:Alb
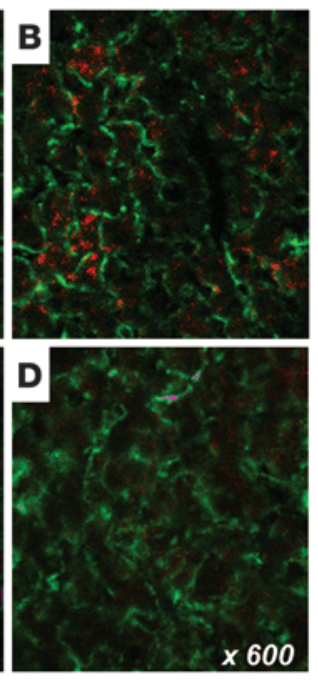

Control
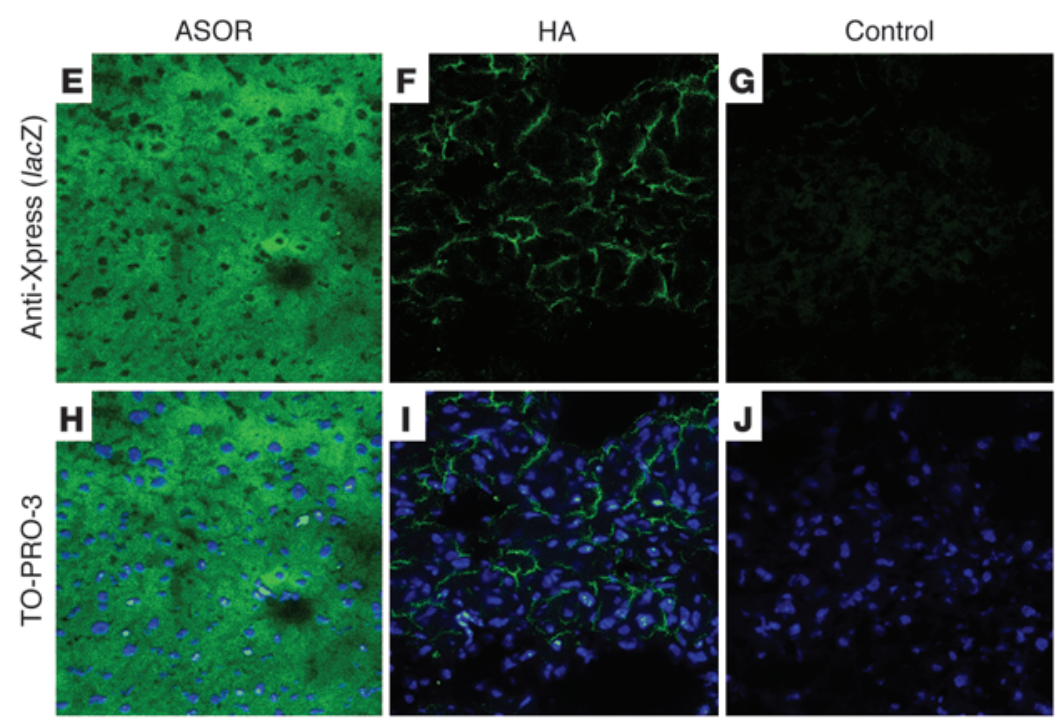

Figure 3

Cell and promoter specificity of nanocapsule targeting in vivo. Eight-week-old male and female mice were administered $100 \mu \mathrm{g}$ of the encapsulated plasmid targeted to liver using ASOR or HA via tail vein injection and sacrificed 1 week after injection. (A-D) $\beta$-gal expression in 6- $\mu \mathrm{m}$ liver cryosections was visualized by immunohistochemical staining using rabbit anti- $\beta$-gal and a mouse cocktail specific for microvessels (78). The micrographs show the red color of the secondary anti-rabbit Qdot 565 conjugate in hepatocytes expressing $\beta$-gal using either the hepatocytespecific SV40:Alb promoter (B) or the constitutive SV40:Ear (C) delivered to hepatocytes via ASOR. In contrast, when LSECs were targeted by HA nanocapsules, no detectable expression of $\beta$-gal using the SV40:Alb promoter occurred (A). (D) Background staining observed in control liver from vehicle-injected mice. The green FITC-labeled microvessels are shown to provide a reference for $\beta$-gal expression. The targeting ligand and plasmid are indicated above and below the respective panels. (E-J) Expression of $\beta$-gal in animals receiving pcDNA3.1 delivered using ASOR ( $\mathbf{E}$ and $\mathbf{H}), \mathrm{HA}(\mathbf{F}$ and $\mathbf{I})$, or vehicle control $(\mathbf{G}$ and $\mathbf{J})$ determined by IHC against the Xpress epitope tag. The positive Xpress signal (green) gives an obvious hepatocyte (E) and LSEC (F) expression pattern, while no staining is observed in the negative vehicle control (G). The merged panels below show the $\beta$-gal expression with the blue nuclei counterstain TO-PRO-3. The targeting ligand is indicated above and the $\mathrm{Ab}$ and nuclear stain on the right.

LSEC-targeted cis FVIII SB-Tns mediate long-term therapeutic expression in knockout hemophilia A mice. We next determined whether selective delivery of nonviral $S B$-Tn vectors to LSECs via HA nanocapsules could correct the bleeding disorder in hemophilia A mice. A cis SBTn pT2/CAGGS-B $\Delta c F V I I I / / I F S B 10$ promoter using the second version of the transposon (pT2) with the mouse eurkaryotic initiation factor 4A1 promoter (IF) driving $S B$ transposase version 10 (SB10) was constructed to express the $\mathrm{B} \Delta \mathrm{cFVIII}$ coding sequence (CDS) from the CAGGS promoter, with the rabbit $\beta$-globin $3^{\prime}$ UTR and poly(A) signal (Table 1). The $S B$ vertebrate Tn system utilizes a "cutand-paste" mechanism to insert the transgene flanked by IR/DRs of the Tn into TA dinucleotide sites in the host genome. The transposition of the Tn from plasmid vector to host genome requires $S B$ transposase, which was expressed from the eukaryotic initiation factor 4A1 promoter carrier on the same plasmid vector (Table 1 and Figure 5). We chose this model because in hemophilia A, endogenous expression of FVIII occurs primarily in LSECs. In addition, LSECs play a unique role in tolerance induction; thus, expression of the B $\Delta$ cFVIII transgene in LSECs might decrease or eliminate inhibitor formation, which is a significant barrier to current gene therapy strategies.

After encapsulation using HA as the targeting ligand, 8-weekold male knockout hemophilia A mice were administered $25 \mu \mathrm{g}$ of the s50-HA pT2/CAGGS-B $\Delta$ cFVIII//IFSB10 nanocapsule via tail vein injection. One week later, the animals were bled and their activated partial thromboplastin times (aPTTs) determined. Mice treated with the pT2/CAGGS-B $\Delta \mathrm{cFVIII} / / \mathrm{IFSB} 10$ construct targeted to LSECs had aPTTs $(26.9 \pm 2.8$ seconds $)$ similar to those of wild-type controls (23.5 \pm 1.3 seconds). In contrast, hemophilia A mice that received HA sugar capsules exhibited significantly $(P<0.001)$ prolonged aPTTs $(47.0 \pm 3.0$ seconds $)$ relative to the wild-type age-matched mice. The mice were bled at various times for the next 11 months and the plasma aPTTs repeated (Figure $6 \mathrm{~A})$. The cis $\mathrm{B} \Delta \mathrm{cFVIII} S B$-Tn-treated hemophilia A mice aPTTs remained steady and were not significantly different from wildtype values for the entire period; control knockout mice continued to exhibit significantly $(P<0.001)$ prolonged aPTTs.

To confirm the lower aPTTs in the treated mice, we used the Coamatic assay to measure FVIII activity via its participation as a cofactor with activated Factor IX (FIXa) in converting Factor X (FX) to the activated form (FXa). Using standard curves generated from pooled wild-type or hemophilia A knockout mouse plasma, we determined that hemophilia A mice injected with the HA-targeted $\mathrm{B} \Delta \mathrm{cFVIII} F$ FIII $S B$-Tn showed activities that ranged from $87 \%$ to $135 \%$ of wild-type mouse values over the 11 -month study period (Figure 6B). In contrast, no activation of FX was detectable using plasma from control untreated knockout mice or at any of the dilutions used to generate the standard curves. We used a tail clip assay to determine bleeding times (31) on a separate group $(n=8)$ of treated hemophilia A mice that showed FVIII activities ranging from $93 \%$ to $146 \%$ of wild-type levels $(119.0 \% \pm 18.5 \%)$. The amount of blood loss determined as free hemoglobin $(0.23 \pm 0.07$, 

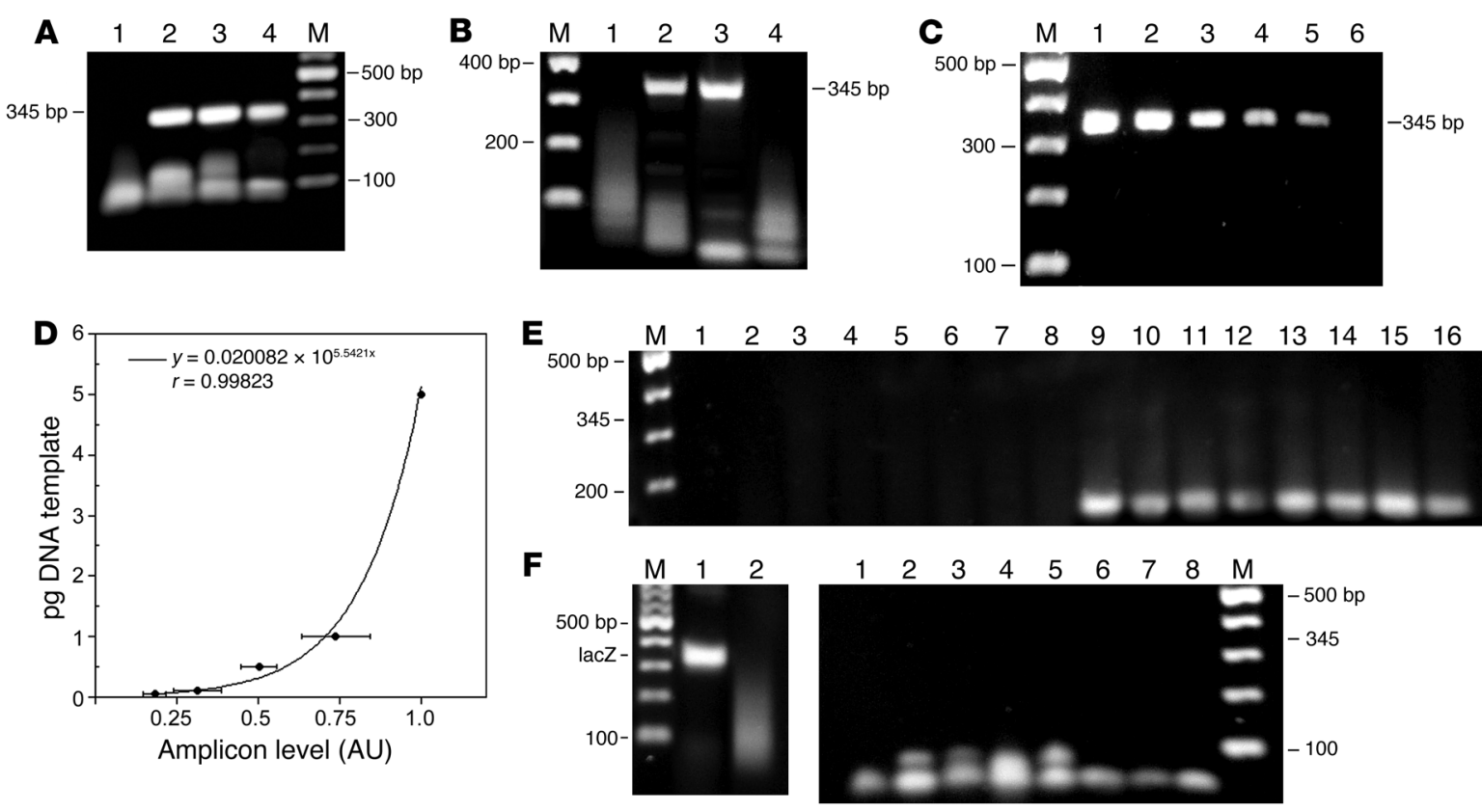

\section{Figure 4}

PCR analysis of DNA from livers of male and female mice injected with ASOR or HA nanocapsules. (A) PCR amplification of the prokaryotic $\beta$-gal CDS. Lane 1, DNA from vehicle-injected control; lanes 2 and 3, ASOR nanocapsules containing pSV40:Alb-lacZ and pSV40:Ear-lacZ, respectively; lane 4, HA nanocapsules containing pSV40:Alb-lacZ. (B) RT-PCR of RNA isolated from livers of mice treated with HA (lane 1) or ASOR (lanes 2 and 3) nanocapsules with the lacZ gene controlled by SV40:Alb (lanes 1 and 2) or SV40:Ear promoter (lane 3) or RNA from a vehicletreated control (lane 4). (C) Representative gel of amplicons produced as in A using 5, 1, 0.5, 0.1, 0.05, and 0.01 pg (lanes 1-6, respectively) of pSV40:Alb as template. The size and location of the predicted amplicons are indicated at left $(\mathbf{A})$ and at right (B and $\mathbf{C})$. M, 2-log DNA ladder, with bands in 100-bp increments. (D) Densitometric data from 4 independent dilution and amplifications using the DNA template concentrations listed in $\mathbf{C}$. The data points are mean $\pm \mathrm{SD}$, with the best-fit curve equation and correlation coefficient shown. (E) Examination of other tissues by PCR. PCR amplification of lacZ using the same primers as for $\mathbf{A}$ and DNA from kidney, lung, and spleen (lane 1-3, respectively) from a female mouse treated with pSV40:Alb-lacZ encapsulated using ASOR and vehicle control spleen DNA (lane 4). Kidney, lung, spleen, and testis (lanes 5-8) from a male treated with pSV40:Alb-lacZ encapsulated using HA. Lanes 9-16, apoB control PCR using the same template DNA and presented in the same order. The apoB amplicon and location of the 345-bp lacZ product are shown. (F) RT-PCR assessment of biodistribution. RT-PCR detection of the lacZ mRNA in RNA from the liver of mice (left panel) treated with ASOR-nanoencapsulated pcDNA 3.1/His/lacZ (lane 1) or from vehicle-treated controls (lane 2). RT-PCR of RNA (right panel) isolated from control kidney (lane 1) and kidney, lung, spleen, and testis (lanes 2-5, respectively) from a male treated with ASOR-encapsulated pSV40:Ear; kidney, lung, and spleen (lanes 6-8) from a female treated with ASOR-encapsulated pcDNA3.1/His/lacZ. The location of the 345-bp lacZ PCR product is indicated.

OD $575 \mathrm{~nm}$ ) for the treated mice did not differ significantly from the control wild-type values $(0.24 \pm 0.08)$. However, untreated hemophilia A littermate mice released significantly more hemoglobin $(0.57 \pm 0.08, P<0.001)$ than either the wild-type or treated hemophilia A animals. We also performed Bethesda assays with the remaining plasma samples, and no significant difference was noted between the knockout animals that received the B $\Delta \mathrm{cFVIII}$ $S B$-Tns and wild-type controls (data not shown).

Identification of SB-mediated genomic transposition sites of $p$ T2/CAGGS$B \triangle c F V I I I$. It was important to exclude the possibility that prolonged expression of the B $\Delta \mathrm{cFVIII}$ in LSECs was a result of episomal or randomly integrated $S B$-Tn vectors. Thus, we isolated DNA from the livers and verified the genotype of the knockout hemophilia A and wild-type mice by PCR (Figure 7A). SB10 CDS was determined by PCR using DNA isolated from livers 1 week after treatment with the cis DsRed2 SB-Tn; and from hemophilia A mice treated with pT2/CAGGS-B $\triangle$ cFVIII//IFSB10. The results clearly demonstrated presence of the $S B 10$ CDS in DNA isolated at 1 week (Figure 7B), while no detectable amplicons for $S B 10$ were observed in livers at 50 weeks, suggesting that episomal or randomly integrated vec- tors were not responsible for the FVIII activity. The DNA sequence flanking the Tn IR/DRs was determined using inverted nested PCR and primer pairs derived from the Tn IR/DRs and internal Tn sequences (Figure 7C). The PCR products were analyzed by agarose gel electrophoresis and indicated that distinct amplicons were present with genomic DNA from the mice that received HA-encapsulated pT2/CAGGS-B $\Delta$ cFVIII//IFSB 10 (Figure 7C, lower panels). In contrast, no products were produced with DNA from the untreated wild-type controls (Figure 7C, lower panels). While the XhoI results indicated the presence of broad bands suggesting a preferred integration spot, these were actually a collection of many individual bands with heavy background amplification.

To determine the identity of the PCR products, the individual bands were excised from the gel, purified, and sequenced. Data from the PCR products revealed that pT2-CAGGS-B $\Delta \mathrm{cFVIII} / /$ $S B 10$ transfected cells exhibited the predicted $S B-T n$ insertional sequence consisting of the Tn IR/DR, duplicated TA, and flanking host genomic DNA (32). Eleven flanking genomic DNA sequences recovered from the cis FVIII SB-Tn-treated knockout mice are shown (Figure 7D). Blast analysis against the mouse genome of 

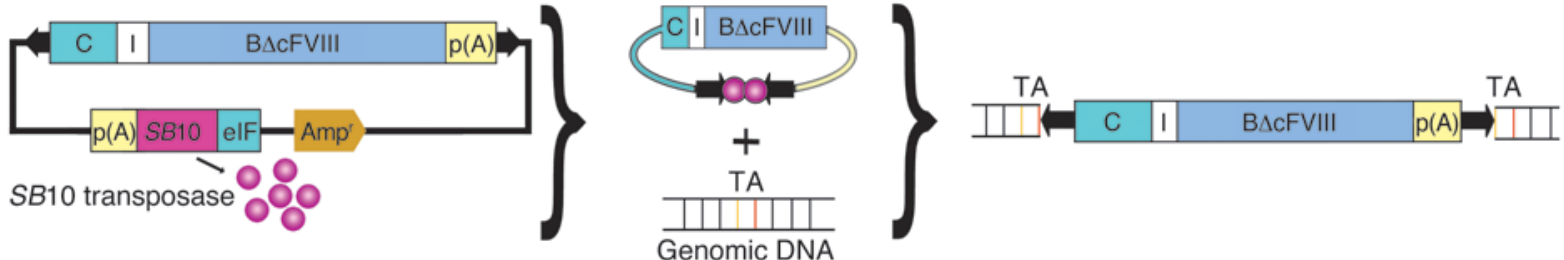

Figure 5

Schematic of FVIII SB-Tn. SB-Tn in cis showing the relative size and position of the 2 eukaryotic expression cassettes (left). IR/DRs (black arrows) flank the CAGGS promoter-driven (C) B $\Delta$ cFVIII transgene that utilizes the SV40 poly $(A)$ signal from the original $B \Delta c F V I I I$ vector. External to the $\mathrm{Tn} I \mathrm{R} / \mathrm{DRs}$, the vector backbone carries the required SB10 transposase expressed from the eukaryotic initiation factor 4A1 promoter (eIF). After transfection, the obligate SB10 transposase (pink) is expressed and binds to the IR/DRs and excises the Tn from the plasmid vector. The transposase cuts and pastes the Tn into random genomic TA dinucleotide sites. I, intron; $p(A)$, polyadenylation sequence.

these Tn insertion sites indicated that they were distributed over 9 chromosomes, 4 intronic and 7 in other regions not associated with identified genes. Of those inserted in intergenic regions, 3 were within $13 \mathrm{~kb}$ of a predicted transcribed region, while the others were more than $75 \mathrm{~kb}$ from any predicted loci. There was no significant similarity between the flanking genomic sequences immediately adjacent to the insertion sites, consistent with the apparent random nature of $S B$-mediated transposition $(32,33)$.

Taken together, these data suggest that use of the novel s50 nm HA FVIII delivery system to LSECs resulted in sustained expression and activity of FVIII. $S B$-mediated genomic transposition of the CAGGS-B $\Delta$ cFVIII Tn in LSECs was efficient enough to correct the bleeding diathesis in knockout hemophilia A mice.

\section{Discussion}

The potential for nonviral gene therapy has been hampered by a lack of adequate in vivo methods for targeted delivery and low efficien- cies of gene transfer. As a result, viral vectors have been the predominant system for in vivo transgene delivery and use in human clinical hemophilia trials (34). However, a number of concerns have emerged regarding their use, including antigenicity, mutagenicity, cost, and defined tropisms (35). Nonviral vectors are emerging as viable alternatives, in the form of 50- to 300-nm diameter DNA complexes with lipids, cationic polymers, or both (36). Unfortunately, critical parameters of size, tissue specificity, charge, and cytotoxicity of synthetic delivery systems in both in vitro and in vivo systems have been difficult to optimize and may contribute to the lack of efficient gene transfer $(6,37)$. In addition, unmethylated cytosine-guanine dinucleotide (CpG) (38), transgene structure, and protein product may also contribute to poor transduction efficiency and reduced persistence of gene expression (39). Although proof-of-principle studies using hydrodynamic delivery have established the potential of $S B$-mediated insertion into the liver genome for long-term gene correction (40), the delivery is nonselective. Thus, an efficient cell type-specific tar-
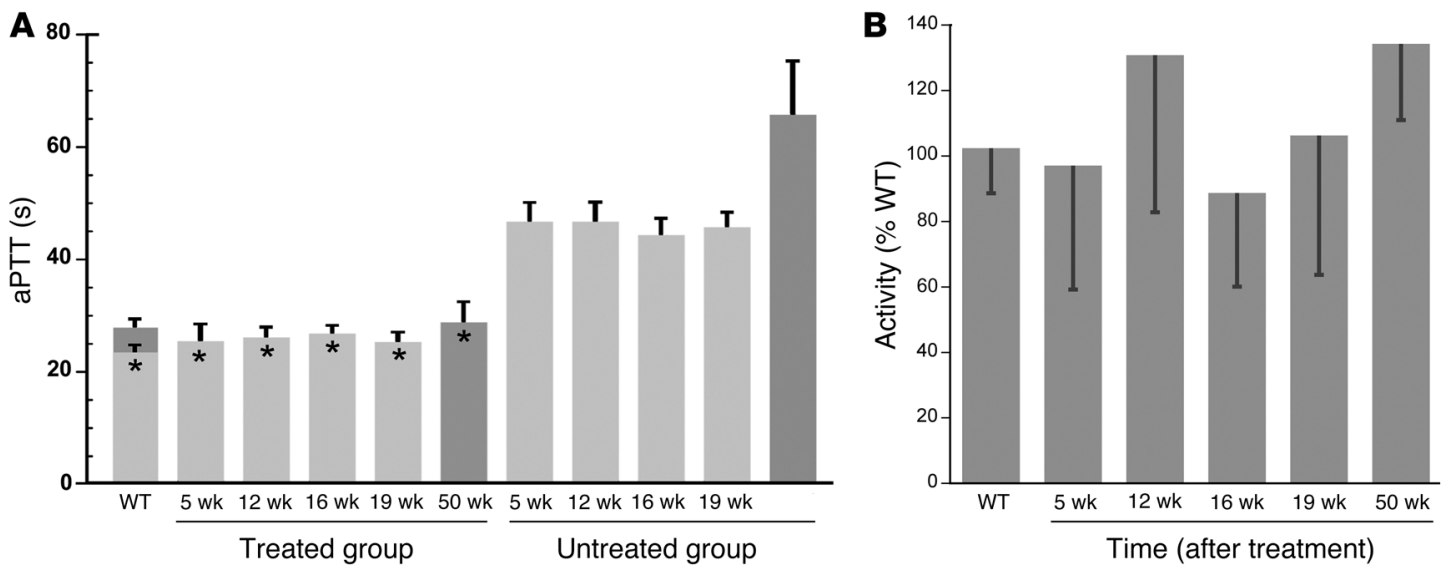

\section{Figure 6}

Targeting of cis CAGGS-BACFVIII SB-Tns to LSECs and correction of the bleeding diathesis in knockout hemophilia A mice. (A) Mice treated with $25 \mu \mathrm{g}$ of $c$ is $S B$-Tn in HA s50 nanocapsules were bled 5, 12, 16, 19, and 50 weeks after injection and aPTTs determined in duplicate as described in Methods. Treated mice $(n=6)$ had aPTTs of $25.5 \pm 3.1$ seconds at 5 weeks and $28.8 \pm 3.7$ seconds at 50 weeks; these were not significantly different from those of age-matched wild-type $(n=3)$ aPTTs of $23.5 \pm 1.3$ seconds ( 5 weeks; light gray) and $27.9 \pm 1.6$ seconds (50 weeks, dark gray). In contrast, untreated mice $(n=3)$ had aPTTs ranging from $46.7 \pm 3.5$ to $65.7 \pm 9.6$ seconds. The data show the mean \pm 1 SD. ${ }^{*} P<0.001$ compared with untreated hemophilia A mice. Far-right dark gray bar, plasma from a separate group of untreated hemophilia A mice collected and assayed with the other 50-week samples. (B) Coamatic determination of FVIII activity in mice. FVIII activity in plasma samples was also determined using the Coamatic assay, which measures the conversion of FX to FXa mediated by FIXa and its cofactor FVIII. The graph shows the mean $\pm 1 \mathrm{SD}$ of values obtained using the procedure outlined in Methods and wild-type mouse plasma as positive control. By 5 weeks after injection, the treated animals showed greater than 95\% wild-type mouse plasma activity; and this increased to greater than $100 \%$ by 50 weeks. In contrast, the plasma from untreated hemophilia A mice exhibited no detectable activity. ANOVA analysis indicated no significant difference between the plasma from treated hemophilia A mice and that from wild-type animals. 


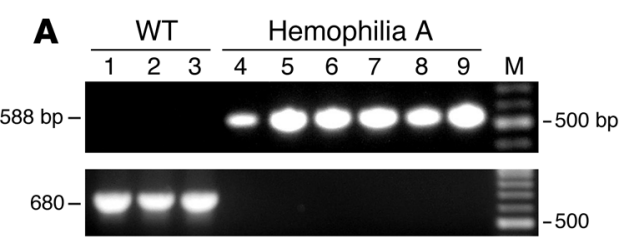

C

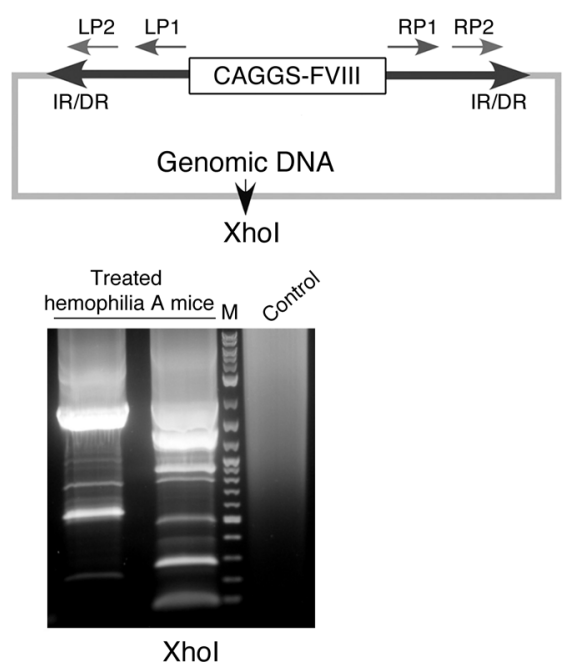

B

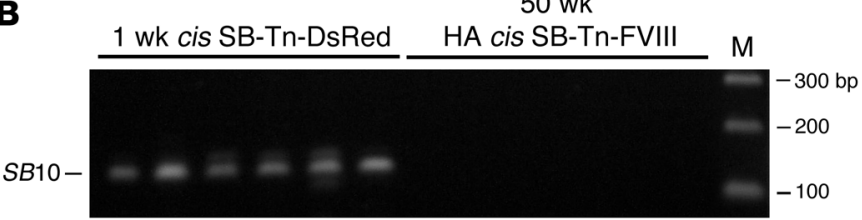

Ncol

Genomic DNA

and transgene
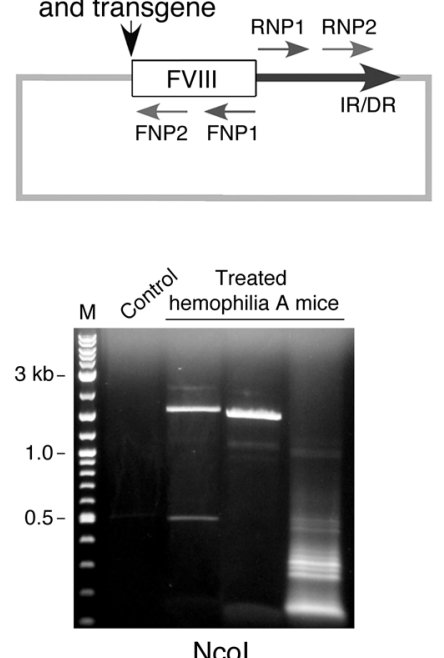

Ncol

\begin{tabular}{|c|c|c|c|}
\hline & Flanking sequences at insertion sites & Location & Nearest transcribed regior \\
\hline & $13 \mathrm{~A} 2^{*}$ & Ryr2 \\
\hline \multicolumn{2}{|c|}{$\begin{array}{l}\text { ACICAAC } \\
\text { ACTTCAACTGTAACTACTTTCTTTTCCAACATGGACTCTGATTTAATGGTTA }\end{array}$} & $113 \mathrm{~A} .2$ & LOC100042708 \\
\hline \multicolumn{2}{|c|}{ ACTTCAACTGTAGATAACCAACATAAAATGAATCCAATAGTTCTTTTGAAGT } & $12 \mathrm{C} 1$ & LOC100039190 \\
\hline \multicolumn{2}{|c|}{ ACTTCAACTGTAAGGATGCTATAGTCATCATGGTGATTTACTTTTTTACACAC } & $16 \mathrm{C} 3.1$ & D0930038003 \\
\hline АCTTCAACT & TTCGCGTTACAAATTCACACAACATATCAACCTGAAGCATT & $8 \mathrm{E} 1^{*}$ & Rnf1 \\
\hline
\end{tabular}

$\operatorname{IR/DR}(\mathrm{R})$

ACTTCAACTGTAAATGGATCTACTTTTTCTTCTCTTTAGAACTGGAAGAGGGT ACTTCAACTGTAAAAACTCTTCCCAGAAGTCACAGGTTATCAAGTGAGAAATC ACTTCAACTGTAGGAGACGCGTTCTGTCTCCTAGAGATGAACGTACTTTGGTG ACTTCAACTGTAATTGTGACTCTGTCTCCTAGAGATGAAGACAAGGAGGATGA ACTTCAACTGTATTGGGCGCTCTTCCGCTTCCTCGCTCACTGACTCGCTGCGC ACTTCAACTGTACAGTGGAACTAACAAAATTAAATGGATCTAACATATTTATA

$\begin{array}{cl}\text { XA7.2 } & \text { EG635295 }(2.2 \mathrm{~kb}) \\ 13 \mathrm{~A} 4^{*} & 3110004 \mathrm{~L} 20 \\ 3 \mathrm{H} 1 & \text { Enpep }(13.7 \mathrm{~kb}) \\ 6 \mathrm{C} 2 & \text { Igkv4-75 }(1.7 \mathrm{~kb}) \\ 2 \mathrm{H} 3 & \text { LOC383692 }(78 \mathrm{~kb}) \\ 6 \mathrm{~B} 3^{*} & \text { Znr2 }\end{array}$

Figure 7

PCR identification of DNA flanking the SB-Tn insertion sites. (A) DNA isolated from the livers of hemophilia A mice injected with HA pT2/CAGGS$\mathrm{B} \triangle \mathrm{CFVIII//IFSB10}$ nanocapsules and wild-type controls served as template using primer pairs specific for the FVIII hemophilia A knockout (top) or the wild-type allele (bottom). (B) Lack of SB10 CDS persistence in the HA-treated knockout mice. PCR amplification of the SB10 CDS was performed (19) using liver DNA isolated from the DsRed2 animals and treated hemophilia A mice. The size or identity of the predicted amplicons and selected bands of the DNA marker (M) are indicated. The time (after injection) that the livers were harvested is indicated above the gels. (C) Schematic of the inverted-nested PCR strategy used to identify DNA flanking the SB-Tn insertion site. The genomic DNA digested by Ncol or Xhol was subjected to self-ligation and the products used as template for the initial inverted PCR amplification with primer pairs RP1/LP1 and RNP1/FNP1 for Xhol- and Ncol-digested DNA, respectively. The second PCR amplification used the Xhol and Ncol initial reactions as template with internal nested primer pairs LP2/RP2 and RNP2/FNP2, respectively. The PCR products were analyzed by agarose gel electrophoresis and visualized by UV light after ethidium bromide staining. The size of the 3 heavy bands is shown to the left of the Ncol gel. (D) Identification of the insertion sites in hemophilia A mice treated with HA-encapsulated pT2/CAGGS-B $\Delta$ cFVIII//IFSB10. The region of the ID/DR of the Tn and the requisite duplicated TA (gray) followed by $40 \mathrm{nt}$ of genomic DNA flanking the identified insertion sites are indicated above the sequences. The chromosomal location established by BLAST analysis is shown at right, and the intronic insertion sites are marked with asterisks. The closest adjacent genes for the other insertions are listed, with the distance in $\mathrm{kb}$ from the $\mathrm{Tn}$ insertion indicated in parentheses if less than $100 \mathrm{~kb}$.

geting system is desirable to fully investigate the potential of $S B$ and other vertebrate Tn vector systems for hepatic gene therapy.

Using a novel dispersion atomization technique (41), we were able to overcome some of the significant barriers for in vivo deliv- ery of plasmid-based nonviral vectors. A particle size of less than $50 \mathrm{~nm}$ is critical for hepatocyte-selective delivery to permit passage through the space of Disse and diminish uptake by Kupffer cells $(25,42)$. The size is substantially smaller than that in other reported 
targeted nanoparticle systems (42-44) and did not require any post-encapsulation modification such as polyethylene glycolyation (PEGylation). The s50 size was achieved over a broad range of plasmid sizes with encapsulation efficiencies approaching or exceeding $90 \%$. However, it must be noted that low encapsulation efficiencies were occasionally observed for a particular formulation run, without a correlative change in the size or charge of the particle. This may have been due to degradation of the plasmid DNA or significant nicking of the plasmid backbone, as only supercoiled DNA is efficiently packaged using this method of formulation.

The overall charge of the particle may be critical to its targeting efficiency in vivo. It is well established that particles with a cationic charge interact with serum proteins, resulting in increased aggregation and rapid elimination via the reticuloendothelial system (45). Particle charge also influences both its toxicity and receptor ligand interaction. The toxicity of polycation:DNA complexes is not fully understood but appears to be mediated not only through complement activation and cytokine release (46), but also via mitochondrial apoptotic mechanisms (27). Reduction of the overall positive charge significantly reduces toxicity of the complexes (45). Thus, the $\zeta$ potential exhibited by the ASOR and HA nanoparticles is likely responsible for their excellent in vivo safety profile.

Anionic particles also show significantly enhanced receptorligand interaction relative to those that are positively charged (28). Yet a fine balance must be achieved between size and overall charge that does not preclude access to or inhibit uptake by the receptor $(43,47)$. Thus, two major advantages of the ASOR and HA nanocapsules were their size and overall charge, both of which are conducive to receptor recognition and cell uptake. These characteristics, coupled with the ability of these nanocapsules to protect the encapsulated plasmids from nuclease activity for extended periods, fulfilled key requirements for effective nonviral plasmid delivery in vivo.

The unique in vivo targeting properties of ASOR and HA to hepatocytes and LSECs, respectively $(48,49)$, allowed us to construct and target identical nanoparticles of encapsulated plasmids by modifying only the ligand moiety. In vivo uptake and cell-specific delivery to hepatocytes and LSECs was consistently observed irrespective of the plasmid cargo. Moreover, the striking lack of tissue biodistribution confirmed the high-level specificity of targeting to the HARE or ASGPr using their respective HA and ASOR ligands. This is in contrast to other ASGPr ligand-targeted hepatocyte delivery systems, in which significant uptake by other organs was also observed $(30,45,50)$. Although HA receptors are present in spleen and lymph nodes (22), differences in receptor characteristics and a significantly greater avidity of LSEC HARE receptors may account for the efficient uptake of the s50 HA nanocapsules by liver (51). Similarly, while receptors capable of recognizing the galactose moiety are present in other tissues $(30,45$, 50 ), the greater avidity of the ASGPr for it natural ligand ASOR versus galactose (by 3 orders of magnitude; ref. 52), in addition to the large number of receptors on hepatocytes, may have accounted for the improved specificity of receptor uptake in vivo. However, it should be noted that some biodistribution of the plasmids may simply not have been detected by PCR, and thus we cannot entirely rule out off-target delivery.

This is the first study to our knowledge in which LSECs were targeted to express FVIII transgene in a knockout mouse model of hemophilia A, confirming the results of an LSEC transplantation study that also reported correction of FVIII deficiency in this mouse model (53). However, 2 previous $S B$-Tn gene therapy studies have described the replacement of FVIII in liver via hydrodynamic delivery (54); and lung endothelial cells using linear polyethylenimine (40). Nevertheless, in targeting only the LSECs, we were able to treat adult immunocompetent hemophilia A mice effectively without apparent induction of inhibitor formation. In contrast, it was recently reported that hydrodynamic delivery of the CAGGS-B domain-deleted human FVIII (huFVIII) SB-Tn resulted in significant inhibitor formation (54). In addition, FVIII inhibitory Abs have been detected in adult hemophilia A mice that were administered canine or human FVIII-expressing transgenes (55). However, the mice used in this study came from the same colony as those reported previously (54). Although the problem of inhibitor formation was overcome by neonatal tolerization of the mice with recombinant huFVIII protein, it continues to be a major obstacle in FVIII gene replacement strategies in animal models (34), requiring additional approaches for tolerization $(56,57)$. In fact, in a recent adeno-associated virus study, longterm persistent FVIII expression in adult dogs was achieved in the absence of inhibitor formation (58). However, the levels of FVIII were not always in the therapeutic range.

Endothelial cells have been used as a target for FVIII gene replacement in both ex vivo $(59,60)$ and in vivo $(40)$ approaches. However, inhibitor formation was problematic even when the $S B$-Tn was administered to neonates in order to promote tolerization (40). Interestingly, inhibitor formation and immune clearance of the transplanted endothelial cells using an ex vivo strategy depended on the cell type and promoter $(59,60)$. Circulating platelets expressing the human B domain-deleted FVIII from a platelet-specific promoter were able to correct the bleeding diathesis in hemophilia A knockout mice in the absence of inhibitor formation over an 11-month period (60). In contrast, expression of a B domain FVIII CDS in blood outgrowth endothelial cells (BOECs) by the thrombomodulin regulatory element still required a tolerizing regimen in hemophilia A mice, and expression was limited to 27 weeks due to clearance of the transduced cells (59). Interestingly, in mice that received the engineered platelets, plasma FVIII was undetectable, suggesting that the lack of secretion of the protein rather than the use of a tissue-specific promoter was responsible for absence of inhibitor formation. Thus, our data suggest that cell-specific targeting of an FVIII transgene to LSECs somehow promotes tolerization and/or prevents formation of inhibitory Abs in immunocompetent hemophilia A animals. As the LSECs play a unique role in tolerance induction, it is conceivable that production of an immunogenic protein by these cells promotes tolerization $(61,62)$. In addition, it may be that the production/ processing/secretion of FVIII in LSECs does not trigger Ab formation, in part, because they are an endogenous site of production $(9,53,63)$. Most notably, it was reported that LSEC transplantation and engraftment of approximately $10 \%-20 \%$ of the hepatic LSEC population was enough to correct the bleeding phenotype in hemophilia A mice (64). Finally, it was recently reported that induced pluripotent stem (iPS) cell-generated wild-type syngeneic endothelial cells engrafted in the liver sinusoids of hemophilia A mice and provided complete correction of the bleeding diathesis (65). Taken together, these data suggest that LSECs are an appropriate target cell for successful correction of the FVIII deficiency by gene therapy or cell transplantation.

The ability to achieve persistent correction of aPTTs and normal levels of FVIII for almost 1 year in hemophilia A knockout 
animals is an important observation. However, any vector that inserts DNA into the host genome has the potential for insertional mutagenesis via gene disruption or activation of flanking chromosomal sequences. To date, the genomic $S B$-mediated insertion profile, although not entirely random for the TA dinucleotide, suggests that $S B$ preferentially inserts into nontranscribed and intronic regions of the genome $(33,66,67)$. This may be related to its preference for TA-rich sequences $(68,69)$ and/or the preferential affinity of the transposase for heterochromatin (70). While activation of adjacent flanking genomic sequences has not been described with $S B$-Tns, epigenetic modification in the form of hypomethylation of flanking sequences has been reported (71), although no untoward effects were noted $(72,73)$. In addition, no adverse events resulting from $S B$-Tn insertional mutagenesis have been identified $(15,40)$.

We have utilized LSEC-targeted delivery of SB-Tns to treat FVIIIdeficient knockout mice. A similar approach could be developed for delivery of transgenes solely to hepatocytes for treatment of such diseases as $\alpha_{1}$-antitrypsin deficiency, hemophilia B, ornithine transcarbamylase deficiency, and Crigler-Najjar syndrome type I. Other unique ligand-receptor interactions may uncover additional target cells for which the nanocapsules can deliver a variety of cargos, including overexpressing transgenes or small interfering RNAs. The combination of a novel cell-specific nanocapsule delivery system with the unique properties of $S B$-Tns provides the opportunity for using nonviral gene therapy as an effective treatment for hemophilia A as well as a number of other hepatic metabolic diseases. The ability to overexpress FVIII in the absence of inhibitory Abs provides an important step toward successful human clinical trials $(2,74)$.

\section{Methods}

Plasmids and SB-Tns. Plasmids were obtained from commercial vendors, or the constructs were generated using blunt-ended cloning following use of Klenow enzyme (New England BioLabs) according to the manufacturer's protocol. The reporter DsRed2 and SB10 CDS were excised from the Clontech DsRed2 and CMVSB10 vectors, respectively, as BamHI, and EcoRI fragments. The CAGGS-driven genes were generated by blunt-end cloning of the relevant CDS into the EcoRI cloning site of the CAGGS vector (24). The mouse eukaryotic initiation factor $4 \mathrm{~A} 1$ promoter-driven (IF-driven) $S B 10$ and the $\mathrm{pT} 2 / \mathrm{IFSB} 10$ were generated by blunt-end cloning of $S B 10$ CDS into the NcoI/EcoRI-digested pDrive-meIF4A1 vector (InvivoGen). This was followed by ligation of the 1.8-kb PacI SB10 fragment from the IF promoter using the SV40 poly(A) region into the NarI site of the second version of the Tn (pT2) (75). pT2/CAGGS-B $\Delta$ cFVIII//IFSB10 was generated by blunt-end ligation of the 7.2-kb SalI-MluI transgene expression cassette containing the CAGGS promoter, CDS, and poly(A) signal from the CAGGS vector (24) into the NheI cloning site between the IR/DRs. The 6.8-kb pDrive-SV40-bAlb and 5.3-kb pDrive meIF4A1 (InvivoGen), the 5.2-kb pSV $\beta$-gal (Promega), and 8.6-kb pcDNA3.1/His/lacZ (Invitrogen) were used without modification.

All DNA was prepared endotoxin-free using QIAGEN kits according to the recommended protocol. Prior to encapsulation, the plasmids were spun at $31,800 \mathrm{~g}$ at $4^{\circ} \mathrm{C}$ for 15 minutes and the DNA supernatant removed, leaving behind microfine particles from the purification columns. Aliquots of $250 \mu \mathrm{g}$ of plasmid DNA at concentrations of $1-2 \mu \mathrm{g} / \mu \mathrm{l}$ were diluted with sterile Milli-Q water to a volume of $500 \mu \mathrm{l}$ and applied to $100,000-\mathrm{MW}$ Centricon filters (Millipore). The samples were spun until the volume was reduced to $150 \mu \mathrm{l}$. The washed DNA, at a concentration of $1.67 \mu \mathrm{g} / \mu \mathrm{l}$, was retained and recovered for encapsulation.
Nanocapsule formulation. Desialylated human orosomucoid (ASOR) was prepared as previously described (21). HA was purchased from Lifecore Biomedical, and all other reagents used were of the highest purity available. Briefly, $250 \mu \mathrm{g}(1.67 \mu \mathrm{g} / \mu \mathrm{l})$ of washed pT2/CAGGS-DsRed2//CMVSB10 DNA was first complexed with $37.6 \mu \mathrm{g}$ of the branched form of $25-\mathrm{kDa}$ polyethylenimine (PEI) $(1 \mu \mathrm{g} / \mu \mathrm{l})$ (Sigma-Aldrich) and dispersed into $150 \mu \mathrm{l}$ sterile water using a water-insoluble surfactant system consisting of $7.5 \mu \mathrm{g}$ of 2,4,7,9-tetramethyl-5-decyne-4,7-diol (50\% v/v) in DMSO (SE-30; Air Products). After emulsification with a water-miscible solvent, DMSO, the suspension was inverted by dilution by the addition of $750 \mu \mathrm{l}$ of sterile PBS, pH 7.2. The resultant hydrophobic micelles were coated by adsorption with $6.5 \mu \mathrm{g}$ ASOR $(1 \mu \mathrm{g} / \mu \mathrm{l})$ dispersed into the solution prior to spray dispersion atomization (41) into a $25-\mathrm{ml} \mathrm{LiCl}$ salt solution $\left(135 \mathrm{mM} \mathrm{Li}^{+}\right.$, $\left.9 \mathrm{mM} \mathrm{Ca}^{2+}, 500 \mathrm{nM} \mathrm{Bi}^{3+}, 50 \mathrm{nM} \mathrm{Sr}^{2+}, 50 \mathrm{nM} \mathrm{Mg}^{2+}\right)$. After incubation at $4-6{ }^{\circ} \mathrm{C}$ with rotation in the salt solution for $24-48$ hours, the s50 nanocapsules were recovered by centrifugation at $20,000 \mathrm{~g}$ for 2 hours and resuspended in PBS containing $10 \%$ lactitol (w/v) at a concentration of $0.5 \mu \mathrm{g} / \mu \mathrm{l}$ for $0.2-\mu \mathrm{m}$ filter sterilization prior to characterization.

The remaining nanocapsule formulations were prepared using the same method with the following modifications: the amount of 25-kDa PEI used for $250 \mu \mathrm{g}$ of the remaining plasmids were pDrive-meIF4A1, $36.6 \mu \mathrm{g}$; pDriveSV40bAlb, $37.5 \mu \mathrm{g}$; pSV- $\beta$-gal, $36.6 \mu \mathrm{g}$; pcDNA 3.1, $37.6 \mu \mathrm{g}$; and cis pT2/ CAGGS-B $\Delta$ cFVIII, $38.7 \mu \mathrm{g}$. For HA formulations, the ASOR was replaced with $6.5 \mu \mathrm{g} H A(0.57 \mu \mathrm{g} / \mu \mathrm{l})$ to coat the micelles, except for the pcDNA 3.1 and cis PT2/CAGGS-B $\Delta$ cFVIII, which used $12.5 \mu \mathrm{g}$ ASOR $(1 \mu \mathrm{g} / \mu \mathrm{l})$ or HA $(0.57 \mu \mathrm{g} / \mu \mathrm{l})$ per $250 \mu \mathrm{g}$ plasmid. Control capsules were made using trehalose as the capsule cargo. For determination of formulation reproducibility, a minimum of 3 different manufacturing runs for each capsule coating were characterized using the cis $\mathrm{PT} 2 / \mathrm{CAGGS}-\mathrm{B} \Delta \mathrm{cFVIII}$ as cargo.

Nanocapsule size and charge determination. The size of the nanocapsules was determined using a NanoScope II (Digital Instruments) multimode atomic force microscope in tapping mode with a type scanner at $1-\mathrm{kHZ}$ scan rate at ambient temperature. Digital AFM images were acquired from $1 \mathrm{ng} / \mathrm{ml}$ nanocapsule samples dried down on a mica sheet. Measurements of the average elliptical axis were determined from 25 capsules.

For TEM, 200 mesh formvar-coated grids were overlaid with $0.1 \%$ PEI $(750 \mathrm{kDa})$ and allowed to dry. Nanocapsules $(10 \mathrm{ng} / \mathrm{ml})$ in $3.3 \%$ glutaraldehyde were applied to the PEI/formvar grids, incubated at room temperature for 10 minutes followed by 3 water washes, and stained for 1 minute in $0.5 \%$ phosphotungstic acid $(\mathrm{w} / \mathrm{v})$ aqueous solution. Micrographs of the negatively stained nanocapsules were acquired with a Philips CM 12 transmission electron microscope. Diameters were calculated as average values of elliptical axis.

Surface charge was measured on a Zetasizer 4 (Malvern) dynamic light scattering (DLS) device at 20 volts with a 2 -second pause between measurements at a working concentration of $2 \mu \mathrm{g} / \mathrm{ml}$ in $1 \mathrm{mM} \mathrm{KCl}$ (76).

Nuclease protection and efficiency of plasmid encapsulations. HA-encapsulated pSV- $\beta$-gal and pDrive-SV40-bAlb ASOR nanocapsules ( $4 \mu \mathrm{g}$ each) and $4 \mu \mathrm{g}$ of the unencapsulated plasmids were digested with RQ1 DNase (Promega) according to the manufacturer's protocol for 18 hours at $37^{\circ} \mathrm{C}$. DNase digestion was terminated by adding EGTA and heating for 10 minutes at $65^{\circ} \mathrm{C}$. Samples were diluted with an equal volume of buffer from the DNeasy isolation kit (QIAGEN); proteinase $\mathrm{K}$ (proK) was added to $3 \mathrm{mg} / \mathrm{ml}$ concentration and the samples incubated at $56^{\circ} \mathrm{C}$ for 36 hours with vigorous shaking. The samples were processed for DNA recovery using the protocol specified by the DNeasy kit. The DNA was analyzed on $0.7 \%$ agarose gels and visualized using ethidium bromide staining and UV light.

For encapsulation profiles of all but the cis pT2/CAGGS-B $\Delta$ cFVIII, $2.5 \mu \mathrm{g}$ aliquots of nanocapsule were released into a $500-\mu \mathrm{l}$ volume of PBS, $\mathrm{pH} 7.2$, containing $10 \%$ isobutanol $(\mathrm{v} / \mathrm{v})$. Aliquots were rocked at $37^{\circ} \mathrm{C}$, 
and sequential $250 \mu \mathrm{l}$ samples were collected. Samples were extracted with 1 volume of isobutanol and plasmid DNA recovered by overnight proK digestion at $56^{\circ} \mathrm{C}$. Additional extraction and column chromatography (QIAGEN) of the aqueous DNA fraction was performed with the recycled eluate to improve final recovery. For the cis pT2/CAGGS-B $\Delta$ cFVIII cargo, the capsules were first treated with Biobeads to remove the surfactant for 2 hours at $25^{\circ} \mathrm{C}$. The capsules were then incubated for 6 hours in $1 \mathrm{M}$ sodium hydroxide at $80^{\circ} \mathrm{C}$, prior to neutralization and incubation in $0.1 \mathrm{M} \mathrm{HCl}$ for 24 hours. DNA concentrations were determined using a colorimetric microplate assay using Burton's diphenylamine method (77). Three independent determinations were performed in duplicate.

In vivo delivery of $H A$ and ASOR nanocapsules expressing DsRed2. All animal studies were approved by the Institutional Animal Use and Care Committee of the University of Minnesota. Adult male and female C57BL/6 mice $(\sim 20 \mathrm{~g})$ were administered HA- or ASOR-coated s50 particles resuspended in PBS containing $10 \%$ lactitol (w/v) at a concentration of $0.5 \mu \mathrm{g} / \mu \mathrm{l}$ via tail vein injection, using a slow infusion rate. Adult C57BL/ 6 mice $(n=3 /$ group $)$ received $100 \mu \mathrm{g}$ in a $200-\mu 1$ volume of $\mathrm{pT} 2 / \mathrm{DsRed} 2 / /$ CMVSB10 in either HA or ASOR nanocapsules. The animals were sacrificed at 1 week and the liver and other organs removed for processing. Thin sections $(6 \mu \mathrm{m})$ were cut and fixed for 10 minutes in $-20^{\circ} \mathrm{C}$ acetone, followed by 3 PBS washes at $4^{\circ} \mathrm{C}$. The LSECs were identified by IHC using anti-CD14 primary $\mathrm{Ab}$, specific for the discontinuous liver endothelial cells (29), and a Cy5-labeled secondary Ab. Additional cryosections of the ASOR nanocapsule-treated livers were processed for staining of hepatocyte nuclei using SYTOX green (Invitrogen). Images were acquired using a Bio-Rad MRC1000 Confocal Microscope. For Western blot analysis, $100 \mu \mathrm{g}$ total protein/lane was separated by SDS 12\% PAGE and electrophoretically transferred to nitrocellulose membranes. DsRed2 was detected by ECL, using SuperSignal West Dura Substrate (Pierce, Thermo Scientific) with polyclonal rabbit anti-DsRed Ab (632496; Clontech) and HRP-conjugated goat anti-rabbit secondary Ab (19). Purified recombinant DsRed protein $(0.4 \mu \mathrm{g}$, liver; or $0.08 \mu \mathrm{g}$, other tissues) (Clontech) was used as a positive control. The lane loading control, $\beta$-actin, was detected using the conditions previously described (67).

For short-term $(n=10)$ toxicity studies, male and female mice $(\sim 20 \mathrm{~g})$ were injected with $200 \mu \mathrm{g}$ of ASOR- or HA-encapsulated pT2/DsRed2// IFSB 10 in a volume of $400 \mu \mathrm{l}$ via tail vein. Animals were sacrificed 72 hours later, blood collected, and standard chemistries and hemograms performed by the University of Minnesota-Fairview Hospital laboratory. For longerterm toxicity ( $n=3 /$ group), adult mice $(20 \mathrm{~g})$ were administered $100 \mu \mathrm{g}$ of ASOR or HA encapsulated pDrive-meIF4A1 and sacrificed 3 months later. Liver, lung, kidneys, heart, and spleen were removed and processed for paraffin embedding. Sections $(4 \mu \mathrm{m})$ were cut, stained with $\mathrm{H} \& \mathrm{E}$, and examined by light microscopy.

Tissue distribution in vivo of HA and ASOR. Mice ( $n=3$ /group) received 100 $\mu \mathrm{g}$ of ASOR-targeted nanocapsules containing lacZ driven by the SV40: $\mathrm{Alb}$, the SV40:Ear, or HA-targeted nanocapsules containing lacZ under the control of the hepatocyte-specific SV40:Alb promoter. One week after injection, liver, kidney, spleen, lung, heart, and testes were removed and DNA and RNA isolated from a section of each organ. Liver cryosections of $6 \mu \mathrm{m}$ were also immunohistochemically stained using an anti- $\beta$-gal rabbit $\mathrm{Ab}$ (Fitzgerald) at a 1:50 dilution, followed by the secondary goat anti-rabbit Qdot 565 conjugate. The blood microvessel cocktail consisted of a 1:50 dilution each of rat anti-mouse CD31, CD34, and CD105 (78). The bridging $\mathrm{Ab}$ was FITC-conjugated donkey anti-rat, followed by secondary $\mathrm{Qdot}$ 525-conjugated (Invitrogen) goat anti-FITC Ab. One week after injection with ASOR or HA nanocapsules containing pcDNA 3.1/His/lacZ, the animals were sacrificed and organs removed for processing. The Xpress epitope tag was detected in liver cryosections using anti-Xpress Ab (Invitrogen) at a 1:50 dilution, followed by secondary Abs FITC-conjugated donkey antimouse (1:200) and A488-conjugated goat anti-FITC (1:800). All primary Ab incubations were for 1 hour and secondary $\mathrm{Ab}$ incubations for 30 minutes. All secondary fluorescent conjugates were from Jackson ImmunoResearch Laboratories Inc. TO-PRO-3 (Invitrogen) nuclear counterstaining was performed according the manufacturer's recommended protocol. Confocal images were collected on a Nikon C1si microscope at 600 power.

DNA was isolated from livers, and $0.5 \mu \mathrm{g}$ was used as template for PCR amplification of $345 \mathrm{bp}$ of the prokaryotic $\beta$-gal CDS using primers $5^{\prime}$ TACTGTCGTCGTCCCCTCAA-3' and 5'-ATAACTGCCGTACTCCAAC-3'. Reactions were performed using Expand High Fidelity polymerase (Roche), using deoxyribonucleotide triphosphates (dNTP) and enzyme concentrations recommended by the manufacturer. After 3 minutes denaturation at $95^{\circ} \mathrm{C}$, the DNA was amplified for 35 cycles of $95^{\circ} \mathrm{C}$ for 45 seconds; $59^{\circ} \mathrm{C}$ for 20 seconds; $72^{\circ} \mathrm{C}$ for 45 seconds, with a final extension for 7 minutes at $72^{\circ} \mathrm{C}$. For organs other than liver, the DNA template was increased to $1.0 \mu \mathrm{g}$. PCR for apoB and SB10 was performed as outlined in ref. 19 using $0.75 \mu \mathrm{g}$ of DNA template. All amplifications were conducted in duplicate for each animal from 2 independent DNA isolations.

To determine the limits of DNA detection, 4 separate serial dilution sets from duplicates of 2 independent plasmid DNA isolations, ranging from 5 pg to $1 \mathrm{fg}$ of cis pT2/CAGGS- $\triangle \mathrm{BcFVIII}$, were amplified under the same conditions as the animal DNA samples including $1.0 \mu \mathrm{g}$ of genomic control DNA in each reaction. Aliquots of $15 \mu \mathrm{l}$ representing one-third of the reaction mixture were subjected to agarose gel electrophoresis, staining with ethidium bromide, and visualization by UV light, with digital image captured by a Kodak Digital imaging station. Quantitation was performed in NIH image J version 1.38i (http://rsbweb.nih.gov/ij/) and the data analyzed using KaleidaGraph version 3.6.4 (Synergy Software). Normalization between gels was accomplished by loading an identical amount of the NEB ladder on all gels and using the density of the 500and 400-bp markers as internal standards.

Liver or other organ total RNA $(2.0 \mu \mathrm{g})$ isolated by TRIzol (Invitrogen) was digested using RQ1 DNase (Promega) to eliminate any remaining episomal DNA vectors. After 30 minutes at $37^{\circ} \mathrm{C}$, the DNase was inactivated by incubation of the reactions at $65^{\circ} \mathrm{C}$ for 15 minutes, followed by reextraction using TRIzol-LS and precipitation with ethanol. The DNasetreated total RNA, 0.25 or $0.5 \mu \mathrm{g}$ from liver or $1.0 \mu \mathrm{g}$ from other tissues, was used as the template to perform RT-PCR using the Titan One Tube RT-PCR system (Roche) using lacZ primers 5'-TACTGTCGTCGTCCCCTCAA-3' and 5'-ATAACTGCCGTACTCCAAC-3', predicted to amplify a 345base portion of the lacZ CDS. The PCR amplification was performed using an RT step at $50^{\circ} \mathrm{C}$ for 30 minutes, followed by denaturation at $94^{\circ} \mathrm{C}$ for 3 minutes and 35 cycles of $94^{\circ} \mathrm{C}, 45$ seconds; $55^{\circ} \mathrm{C}, 30$ seconds; $68^{\circ} \mathrm{C}$, 45 seconds, with a final extension at $68^{\circ} \mathrm{C}$ for 7 minutes. PCR and RT-PCR reaction products were separated on 1.2\% Agarose 1000 (Invitrogen) gels and the DNA visualized using ethidium bromide staining and UV light.

Phenotypic characterization of hemophilia A mice treated with HA-LSEC-targeted pT2/CAGGS-BDcFVIII//IFSB10. Male exon 16-knockout hemophilia A mice (79) were administered $25 \mu \mathrm{g}$ of the HA-encapsulated pT2/CAGGS$\mathrm{B} \triangle \mathrm{cFVIII//IFSB10}$ or an equivalent volume of HA-sugar capsules in a volume of $50 \mu$ l. Mice were bled retro-orbitally 1, 5, 12, 16, 19, and 50 weeks after treatment using a $10 \%$ volume of $0.1 \mathrm{M}$ sodium citrate as an anticoagulant and mixed immediately after collection. After centrifugation at $1,000 \mathrm{~g}$ for 10 minutes at room temperature, the plasma was flash frozen in $50-\mu \mathrm{l}$ aliquots in liquid nitrogen prior to storage at $-80^{\circ} \mathrm{C}$. Functional FVIII activity was determined by aPTT according to the manufacturer's instructions (Diagnostica Stago). Briefly, $40 \mu \mathrm{l}$ of a 1:1 dilution of aPTT reagent (bioMérieux) was added to a $40-\mu$ l aliquot of 3 -fold-diluted plasma and incubated at $37^{\circ} \mathrm{C}$ for 5 minutes. Clotting was initiated by the addi- 
tion of $25 \mathrm{mM}$ calcium chloride, with coagulation times measured using an ST4 coagulometer (Diagnostica Stago). All samples were studied in duplicate, and means were calculated. Internal standards were established using pooled plasma isolated from wild-type mice.

FVIII activity was also determined using the end-point method of the photometric COAMATIC Factor VIII kit (Chromogenix). Reference plasma was isolated from both wild-type C57BL/ 6 and knockout hemophilia mice via cardiac puncture and stored at $-80^{\circ} \mathrm{C}$. High-range dilutions of the reference plasma were made with the manufacturer's buffer at 1:56, 1:80, $1: 160$, and 1:320. Plasma samples from treated and control hemophilia A mice and wild-type controls were thawed at $25^{\circ} \mathrm{C}$ and diluted $1: 100$ in the buffer provided. The samples and reference plasmas $(50 \mu \mathrm{l})$ were incubated at $37^{\circ} \mathrm{C}$ for 4 minutes and the assay performed as specified by the manufacturer. The OD was read at $405 \mathrm{~nm}$ and analyzed using SOFTmax PRO (Molecular Dynamics, Beckman Coulter).

Tail-clip bleeding time assays were performed as described previously (31), with the following modifications. The prewarmed tails $\left(2\right.$ minutes at $\left.37^{\circ} \mathrm{C}\right)$ were cut at diameters of $2.5 \mathrm{~mm}$ and immersed in $13 \mathrm{ml}$ of prewarmed saline. Tails were left immersed for 10 minutes, then removed, and direct pressure was applied for 2 minutes to promote hemostasis. After 1 hour, any tails showing incomplete hemostasis were cauterized. Red blood cells were collected by centrifugation of the saline samples at $520 \mathrm{~g}$ for 10 minutes at $4^{\circ} \mathrm{C}$. Following removal of the saline, the pellets were lysed in $6 \mathrm{ml}$ lysis buffer (10 $\mathrm{mM} \mathrm{KHPO}_{4}, 150 \mathrm{mM} \mathrm{NH}_{4} \mathrm{Cl}, 1 \mathrm{mM}$ EDTA) for 10 minutes at room temperature. The samples were centrifuged to remove cell debris, and the supernatants diluted 20-fold in lysis buffer and checked for absorbance at $575 \mathrm{~nm}$. The untreated hemophilia A controls were littermates of the treated animals, and the wild-type controls were age-matched C57BL/6 mice.

For modified Bethesda assays, the plasma samples $(50 \mu \mathrm{l})$ from each of the groups was mixed with $50 \mu \mathrm{l}$ normal canine plasma at room temperature. Samples were vortexed and divided into two, and one half was assayed immediately, while the other was incubated at $37^{\circ} \mathrm{C}$ for 2 hours prior to analysis. Forty microliters of mouse plasma:normal canine plasma mixed sample was added to $40 \mu \mathrm{l}$ aPTT reagent (bioMérieux) and incubated at $37^{\circ} \mathrm{C}$ for 5 minutes. Clotting was initiated by the addition of $25 \mathrm{mM}$ calcium chloride and coagulation times measured with an ST4 coagulometer (Diagnostica Stago). A positive control assay with a known FVIII inhibitor resulted in 276.9 Bethesda units.

PCR analysis of genotype and SB-mediated CAGGS-BACFVIII Tn insertion sites. Liver genomic DNA was purified using the DNeasy Tissue Kit from QIAGEN according to the manufacturer's recommendation, and $0.25 \mu \mathrm{g}$ was used as template for PCR amplification of exon 16 spanning the neomycin insertion site into the exon 16-deleted FVIII gene (79). The forward primer, 5'-TCAAAGTGGGGTCTTCCATCTG- 3 ', is specific for the inserted neomycin gene, while the reverse primer, 5'-TGAGGAGAGAACTGGCTGAGTGAC-3', is located in exon 17, and the predicted product was $588 \mathrm{bp}$. The wild-type gene was amplified using the primer pair 5'-TGCAAGGCCTGGGCTTATTT-3' and 5'-GAGCAAATTCCTGTACTGAC-3', with a predicted 680-bp PCR product. Reactions were performed using Expand High Fidelity polymerase, with dNTP and enzyme concentrations recommended by the manufacturer. For PCR of the neomycin insertion site, after 3 minutes denaturation at $94^{\circ} \mathrm{C}$, the DNA was amplified for 35 cycles of $94^{\circ} \mathrm{C}$ for 45 seconds; $56^{\circ} \mathrm{C}$ for 20 seconds; $72^{\circ} \mathrm{C}$ for 45 seconds, with a final extension for 7 minutes at $72^{\circ} \mathrm{C}$. For the wild-type FVIII gene, amplification conditions were identical to those previously described (79). PCR products were analyzed on a $1 \%$ agarose gel, followed by ethidium bromide staining, and visualized using UV light.
Genomic DNA $(2 \mu \mathrm{g})$ purified from the livers of treated hemophilia A or wild-type control mice was digested using either XhoI or NcoI in a final volume of $200 \mu \mathrm{l}$, at $37^{\circ} \mathrm{C}$ overnight. The products were purified using QIAquick PCR Purification Kit from QIAGEN, as specified by the manufacturer. The DNA was eluted into $50 \mu \mathrm{l}$ buffer and $2 \mu \mathrm{g}$ ligated using 2,400 U of T4 DNA ligase (Promega) in $400 \mu$ l of $1 \times$ T4 ligase buffer overnight at $16^{\circ} \mathrm{C}$. The ligation products were purified using the QIAquick PCR Purification Kit, and the DNA was eluted in $30 \mu \mathrm{l} \mathrm{buf-}$ fer. Using $10 \mu \mathrm{l}$ of the eluted DNA as template, the first inverted PCR amplification was performed in $100-\mu 1$ reaction volume by using Expand High Fidelity polymerase with the dNTP and enzyme concentrations recommended by the manufacturer. After 3 minutes denaturation at $94^{\circ} \mathrm{C}$, the DNA was amplified for 21 cycles of $94^{\circ} \mathrm{C}$ for 30 seconds; $58^{\circ} \mathrm{C}$ for 30 seconds; $68^{\circ} \mathrm{C}$ for 4 minutes, with a final extension for 7 minutes at $68^{\circ} \mathrm{C}$. After cleanup with the QIAquick PCR Purification Kit, $15 \mu \mathrm{l}$ of the eluted DNA served as template for a second PCR reaction using the appropriate nested primer pairs in $100 \mu \mathrm{l}$, under standard conditions for Expand High Fidelity polymerase. After the 3 minutes denaturation, PCR was performed for 40 cycles using the same cycle parameters. The products from the PCR reactions were separated on 1.0\% agarose gel, stained with ethidium bromide, and visualized by UV light. The relevant DNA fragments were excised from the gel, purified using the QIAGEN Gel Isolation Kit according to the manufacturer's protocol, and sequenced using the nested primers.

Statistics. Statistical analysis was performed using GraphPad InStat version 3.5 for OS X (GraphPad Software) for the ANOVA and Tukey-Kramer multiple comparisons tests. $P$ values less than 0.05 were considered significant.

\section{Acknowledgments}

We thank members of the Steer/Kren laboratory for helpful discussions. Portions of this work were carried out at the Institute of Technology Characterization Facility, University of Minnesota, a member of the National Science Foundation-funded Materials Research Facilities Network, and College of Biological Sciences Imaging Center at the University of Minnesota. This work was supported in part by National Heart, Lung, and Blood Institute (NHLBI)/National Hemophilia Foundation (NHF) Rose Bender Fund grant HL0258591-01 to R.P. Hebbel and C.J. Steer; NHLBI grant R01-HL081582-02 to C.J. Steer; NIDDK grant R01DK067436-01 to B.T. Kren; Department of Defense grant W81XWH-05-C-0084 to G.M. Unger; and a generous gift from Eleanor and Harold Hamilton to C.J. Steer.

Received for publication October 24, 2007, and accepted in revised form April 22, 2009.

Address correspondence to: Betsy T. Kren, Division of Gastroenterology, Hepatology and Nutrition, University of Minnesota Medical School, MMC 36, VFW Cancer Research Center, Room V354, 406 Harvard St. SE, Minneapolis, Minnesota 55455, USA. Phone: (612) 626-4255; Fax: (612) 625-5620; E-mail: krenx001@umn.edu. Or to: Clifford J. Steer, Division of Gastroenterology, Hepatology and Nutrition, University of Minnesota Medical School, MMC 36, VFW Cancer Research Center, Room V357, 406 Harvard St. SE, Minneapolis, Minnesota 55455, USA. Phone: (612) 624-6648; Fax: (612) 625-5620; E-mail: steer001@umn.edu.
1. Thomas, C.E., Ehrhardt, A., and Kay, M.A. 2003. Progress and problems with the use of viral vectors for gene therapy. Nat. Rev. Genet. 4:346-358.

2. Ponder, K.P. 2006. Gene therapy for hemophilia.
Curr. Opin. Hematol. 13:301-307.

3. Pierce, G.F., Lillicrap, D., Pipe, S.W., and Vandendriessche, T. 2007. Gene therapy, bioengineered clotting factors and novel technologies for hemo- philia treatment. J. Thromb. Haemost. 5:901-906.

4. Hacein-Bey-Abina, S., et al. 2003. LMO2-associated clonal $\mathrm{T}$ cell proliferation in two patients after gene therapy for SCID-X1. Science. 302:415-419. 
5. Raper, S.E., et al. 2003. Fatal systemic inflammatory response syndrome in a ornithine transcarbamylase deficient patient following adenoviral gene transfer. Mol. Genet. Metab. 80:148-158.

6. Lavigne, M.D., and Gorecki, D.C. 2006. Emerging vectors and targeting methods for nonviral gene therapy. Expert Opin. Emerg. Drugs. 11:541-557.

7. Al-Dosari, M.S., Knapp, J.E., and Liu, D. 2005. Hydrodynamic delivery. Adv. Genet. 54:65-82.

8. Budker, V.G., et al. 2006. Mechanism of plasmid delivery by hydrodynamic tail vein injection. II. Morphological studies. J. Gene Med. 8:874-888.

9. Hollestelle, M.J., et al. 2001. Tissue distribution of factor VIII gene expression in vivo - a closer look. Thromb. Haemost. 86:855-861.

10. Xu, L., et al. 2005. Absence of a desmopressin response after therapeutic expression of factor VIII in hemophilia A dogs with liver-directed neonatal gene therapy. Proc. Natl. Acad. Sci. U. S. A. 102:6080-6085.

11. Brown, B.D., et al. 2004. Factors influencing therapeutic efficacy and the host immune response to helper-dependent adenoviral gene therapy in hemophilia A mice. J. Thromb. Haemost. 2:111-118.

12. Rawle, F.E., et al. 2004. Heterogeneity of the immune response to adenovirus-mediated factor VIII gene therapy in different inbred hemophilic mouse strains. J. Gene Med. 6:1358-1368.

13. Ye, P., et al. 2004. Naked DNA transfer of Factor VIII induced transgene-specific, species-independent immune response in hemophilia A mice. Mol. Ther. 10:117-126.

14. Wolff, J.A., and Budker, V. 2005. The mechanism of naked DNA uptake and expression. Adv. Genet. 54:3-20.

15. Ivics, Z., and Izsvák, Z. 2006. Transposons for gene therapy! Curr. Gene Ther. 6:593-607.

16. Dupuy, A.J., Jenkins, N.A., and Copeland, N.G. 2006. Sleeping Beauty: a novel cancer gene discovery tool. Hum. Mol. Genet. 15:R75-R79.

17. Yant, S.R., et al. 2000. Somatic integration and long-term transgene expression in normal and haemophilic mice using a DNA transposon system. Nat. Genet. 25:35-41.

18. Geurts, A.M., et al. 2003. Gene transfer into genomes of human cells by the Sleeping Beauty transposon system. Mol. Ther. 8:108-117.

19. Kren, B.T., et al. 2003. Hepatocyte-targeted delivery of Sleeping Beauty mediates efficient transposition in vivo. Gene Ther. Mol. Biol. 7:231-240.

20. Mikkelsen, J.G., et al. 2003. Helper-Independent Sleeping Beauty transposon-transposase vectors for efficient nonviral gene delivery and persistent gene expression in vivo. Mol. Ther. 8:654-665.

21. Stockert, R.J., et al. 1980. Endocytosis of asialoglycoprotein-enzyme conjugates by hepatocytes. $L a b$. Invest. 43:556-563.

22. Weigel, J.A., Raymond, R.C., McGary, C., Singh, A., and Weigel, P.H. 2003. A blocking antibody to the hyaluronan receptor for endocytosis (HARE) inhibits hyaluronan clearance by perfused liver. J. Biol. Chem. 278:9808-9812.

23. Notley, C., et al. 2002. The canine factor VIII 3'untranslated region and a concatemeric hepatocyte nuclear factor 1 regulatory element enhance factor VIII transgene expression in vivo. Hum. Gene Ther 13:1583-1593.

24. Okabe, M., Ikawa, M., Kominami, K., Nakanishi, T., and Nishimune, Y. 1997. 'Green mice' as a source of ubiquitous green cells. FEBS Lett. 407:313-319.

25. Hara, T., Tan, Y., and Huang, L. 1997. In vivo gene delivery to the liver using reconstituted chylomicron remnants as a novel nonviral vector. Proc. Natl. Acad. Sci. U. S. A. 94:14547-14552.

26. Nishikawa, M., Takemura, S., Takakura, Y., and Hashida, M. 1998. Targeted delivery of plasmid DNA to hepatocytes in vivo: optimization of the pharmacokinetics of plasmid DNA/galactosyl- ated poly(L-lysine) complexes by controlling their physicochemical properties. J. Pharmacol. Exp. Ther 287:408-415

27. Hunter, A.C. 2006. Molecular hurdles in polyfectin design and mechanistic background to polycation induced cytotoxicity. Adv. Drug Deliv. Rev. 58:1523-1531.

28. Lee, R.J., and Huang, L. 1996. Folate-targeted, anionic liposome-entrapped polylysine-condensed DNA for tumor cell-specific gene transfer. J. Biol. Chem. 271:8481-8487.

29. Nakamura, S., et al. 1997. Immunohistochemica studies on endothelial cell phenotype in hepatocellular carcinoma. Hepatology. 26:407-415.

30. Lu, I.L., et al. 2003. Correction/mutation of acid $\alpha$-D-glucosidase gene by modified single-stranded oligonucleotides: in vitro and in vivo studies. Gene Ther. 10:1910-1916.

31. Aljamali, M.N., et al. 2008. Long-term expression of murine activated factor VII is safe, but elevated levels cause premature mortality. J. Clin. Invest. 118:1825-1834.

32. Ivics, Z., Hackett, P.B., Plasterk, R.H., and Izsvák, Z. 1997. Molecular reconstruction of Sleeping Beauty, a Tc1-like transposon from fish, and its transposition in human cells. Cell. 91:501-510.

33. Vigdal, T.J., Kaufman, C.D., Izsvák, Z., Voytas, D.F., and Ivics, Z. 2002. Common physical properties of DNA affecting target site selection of Sleeping Beauty and other Tc1/mariner transposable elements. J. Mol. Biol. 323:441-452.

34. Lillicrap, D., VandenDriessche, T., and High, K. 2006. Cellular and genetic therapies for haemophilia. Haemophilia. 12(Suppl. 3):36-41.

35. Merdan, T., Kopecek, J., and Kissel, T. 2002. Prospects for cationic polymers in gene and oligonucleotide therapy against cancer. Adv. Drug Deliv. Rev. 54:715-758.

36. Lechardeur, D., and Lukacs, G.L. 2002. Intracellular barriers to non-viral gene transfer. Curr. Gene Ther. 2:183-194.

37. Gao, X., Kim, K.S., and Liu, D. 2007. Nonviral gene delivery: what we know and what is next. AAPS J. 9:E92-E104

38. Yew, N.S., et al. 2002. CpG-depleted plasmid DNA vectors with enhanced safety and long-term gene expression in vivo. Mol. Ther. 5:731-738.

39. van Gaal, E.V., Hennink, W.E., Crommelin, D.J., and Mastrobattista, E. 2006. Plasmid engineering for controlled and sustained gene expression for nonviral gene therapy. Pharm. Res. 23:1053-1074.

40. Fernando, S., and Fletcher, B.S. 2006. Sleeping Beau ty transposon-mediated nonviral gene therapy. BioDrugs. 20:219-229.

41. Wang, G., Ahmad, K.A., Unger, G., Slaton, J.W. and Ahmed, K. 2006. CK2 signaling in androgendependent and -independent prostate cancer. J. Cell. Biochem. 99:382-391.

42. Popielarski, S.R., Hu-Lieskovan, S., French, S.W., Triche, T.J., and Davis, M.E. 2005. A nanoparticlebased model delivery system to guide the rational design of gene delivery to the liver. 2 . In vitro and in vivo uptake results. Bioconjug. Chem. 16:1071-1080.

43. Bartlett, D.W., and Davis, M.E. 2007. Physicochemical and biological characterization of targeted, nucleic acid-containing nanoparticles. Bioconjug. Chem. 18:456-468.

44. Mo, Y., Barnett, M.E., Takemoto, D., Davidson, H., and Kompella, U.B. 2007. Human serum albumin nanoparticles for efficient delivery of $\mathrm{Cu}, \mathrm{Zn}$ superoxide dismutase gene. Mol. Vis. 13:746-757.

45. Neu, M., Fischer, D., and Kissel, T. 2005. Recent advances in rational gene transfer vector design based on poly(ethylene imine) and its derivatives. J. Gene Med. 7:992-1009.

46. Tousignant, J.D., et al. 2000. Comprehensive analysis of the acute toxicities induced by systemic administration of cationic lipid:plasmid DNA complexes in mice. Hum. Gene Ther. 11:2493-2513.

47. Rensen, P.C., et al. 2001. Determination of the upper size limit for uptake and processing of ligands by the asialoglycoprotein receptor on hepatocytes in vitro and in vivo. J. Biol. Chem. 276:37577-37584.

48. Findeis, M.A., Wu, C.H., and Wu, G.Y. 1994. Ligand-based carrier systems for delivery of DNA to hepatocytes. Methods Enzymol. 247:341-351.

49. Takei, Y., et al. 1999. Targeted gene transfer to sinusoidal endothelial cells and expression in vivo. Transplant Proc. 31:790-791.

50. Kawakami, S., Yamashita, F., Nishida, K., Nakamura, J., and Hashida, M. 2002. Glycosylated cationic liposomes for cell-selective gene delivery. Crit. Rev. Ther. Drug Carrier Syst. 19:171-190.

51. Fraser, J.R., Laurent, T.C., and Laurent, U.B. 1997. Hyaluronan: its nature, distribution, functions and turnover. J. Intern. Med. 242:27-33.

52. Connolly, D.T., Townsend, R.R., Kawaguchi, K., Bell, W.R., and Lee, Y.C. 1982. Binding and endocytosis of cluster glycosides by rabbit hepatocytes. Evidence for a short-circuit pathway that does not lead to degradation. J. Biol. Chem. 257:939-945.

53. Kumaran, V., et al. 2005. Transplantation of endothelial cells corrects the phenotype in hemophilia A mice. J. Thromb. Haemost. 3:2022-2031.

54. Ohlfest, J.R., et al. 2005. Phenotypic correction and long-term expression of factor VIII in hemophilic mice by immunotolerization and nonviral gene transfer using the Sleeping Beauty transposon system. Blood. 105:2691-2698.

55. Miao, C.H., Ye, P., Thompson, A.R., Rawlings, D.J., and Ochs, H.D. 2006. Immunomodulation of transgene responses following naked DNA transfer of human factor VIII into hemophilia A mice. Blood. 108:19-27.

56. Liu, L., Mah, C., and Fletcher, B.S. 2006. Sustained FVIII expression and phenotypic correction of hemophilia A in neonatal mice using an endothelial-targeted Sleeping Beauty transposon. Mol. Ther. 13:1006-1015.

57. Xu, L., et al. 2007. Immune response after neonatal transfer of a human factor IX-expressing retroviral vector in dogs, cats, and mice. Thromb. Res. 120:269-280.

58. Jiang, H., et al. 2006. Multiyear therapeutic benefit of AAV serotypes 2, 6, and 8 delivering factor VIII to hemophilia A mice and dogs. Blood. 108:107-115.

59. Matsui, H., et al. 2007. Ex vivo gene therapy for hemophilia A that enhances safe delivery and sustained in vivo FVIII expression from lentivirallyengineered endothelial progenitors. Stem Cells. 25:2660-2669.

60. Shi, Q., et al. 2007. Lentivirus-mediated plateletderived factor VIII gene therapy in murine haemophilia A. J. Thromb. Haemost. 5:352-361.

61. Knolle, P.A., and Gerken, G. 2000. Local control of the immune response in the liver. Immunol. Rev. 174:21-34.

62. Knolle, P.A., and Limmer, A. 2003. Control of immune responses by scavenger liver endothelial cells. Swiss Med. Wkly. 133:501-506.

63. Hollestelle, M.J., et al. 2004. Factor VIII expression in liver disease. Thromb. Haemost. 91:267-275.

64. Follenzi, A., et al. 2008. Transplanted endothelial cells repopulate the liver endothelium and correct the phenotype of hemophilia A mice. J. Clin. Invest. 118:935-945.

65. Xu, D., et al. 2009. Phenotypic correction of murine hemophilia A using an iPS cell-based therapy. Proc. Natl. Acad. Sci. U. S. A. 106:808-813.

66. Yant, S.R., et al. 2005. High-resolution genomewide mapping of transposon integration in mammals. Mol. Cell. Biol. 25:2085-2094.

67. Zhu, J., et al. 2007. Erythroid-specific expression of $\beta$-globin by the Sleeping Beauty transposon for sickle cell disease. Biochemistry. 46:6844-6858.

68. Louie, E., Ott, J., and Majewski, J. 2003. Nucleotide 
frequency variation across human genes. Genome Res. 13:2594-2601.

69. Winnard, P., Sidell, B.D., and Vayda, M.E. 2002. Teleost introns are characterized by a high $\mathrm{A}+\mathrm{T}$ content. Comp. Biochem. Physiol. B Biochem. Mol. Biol. 133:155-161.

70. Ikeda, R., et al. 2007. Sleeping Beanty transposase has an affinity for heterochromatin conformation. Mol. Cell. Biol. 27:1665-1676.

71. Park, C.W., Park, J., Kren, B.T., and Steer, C.J. 2006. Sleeping Beauty transposition in the mouse genome is associated with changes in DNA methylation at the site of insertion. Genomics. 88:204-213.

72. Dupuy, A.J., Fritz, S., and Largaespada, D.A. 2001. Transposition and gene disruption in the male germline of the mouse. Genesis. 30:82-88.
73. Carlson, C.M., et al. 2003. Transposon mutagenesis of the mouse germline. Genetics. 165:243-256.

74. Lee, C.A., Lillicrap, D., and Astermark, J. 2006. Inhibitor development in hemophiliacs: the roles of genetic versus environmental factors. Semin. Thromb. Hemost. 32(Suppl. 2):10-14.

75. Cui, Z., Geurts, A.M., Liu, G., Kaufman, C.D., and Hackett, P.B. 2002. Structure-function analysis of the inverted terminal repeats of the Sleeping Beanty transposon. J. Mol. Biol. 318:1221-1235.

76. Allison, S.D., Molina, M.C., and Anchordoquy, T.J. 2000. Stabilization of lipid/DNA complexes during the freezing step of the lyophilization process: the particle isolation hypothesis. Biochim. Biophys. Acta. 1468:127-138.

77. Burton, K. 1956. A study of the conditions and mechanism of the diphenylamine reaction for the colorimetric estimation of deoxyribonucleic acid. Biochem. J. 62:315-323.

78. Nagatsuka, H., et al. 2005. Various immunostaining patterns of CD31, CD34 and endoglin and their relationship with lymph node metastasis in oral squamous cell carcinomas. J. Oral Pathol. Med. 34:70-76.

79. Bi, L., Lawler, A.M., et al. 1995. Targeted disruption of the mouse factor VIII gene produces a model of haemophilia. A. Nat. Genet. 10:119-121.

80. InvivoGen. Tissue-specific promoters. http:// www.invivogen.com/family.php?ID=232\&ID_ cat=7\&ID_sscat=92.

81. Promega.pSV- $\beta$-galactosidase control vector. http:// www.promega.com/catalog/catalogproducts. aspx?categoryname=productleaf_2968ckt=1. 